\title{
Actas correspondientes a las Jornadas "Siniestralidad y morbilidad laboral en carretera. Especial referencia a factores subjetivos (edad, género, discapacidad, tipo de relación de trabajo) y a propuestas de reducción"
}

\author{
celebrada en la Facultad de Derecho de la Universidad de León \\ del 18 al 20 de octubre de 2016
}

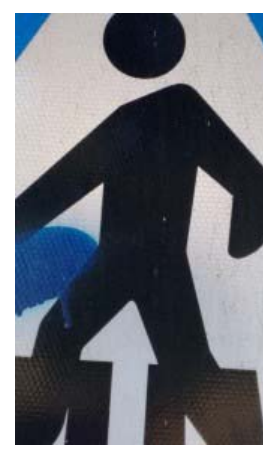

Relatora

BEATRIZ AGRA VIFORCOS

TU Derecho del Trabajo y de la Seguridad Social

Universidad de León

\section{INTRODUCCIÓN}

A lo largo de los días 18,19 y 20 de octubre de 2016 se desarrollaron las Jornadas, organizadas por la Facultades de Derecho y de Ciencias del Trabajo de la Universidad de León y financiadas por la Junta de Castilla y León, supra indicadas: "Siniestralidad y morbilidad laboral en carretera. Especial referencia a factores subjetivos (edad, género, discapacidad, tipo de relación de trabajo) y a propuestas de reducción".

Estructuradas en tres grandes bloques temáticos, en la jornada primera se abordó la siniestralidad en carretera en España con carácter general; en la segunda se analizó la siniestralidad y morbilidad laboral en carretera, y la tercera se dedicó, por una parte, a valorar la posible incidencia de factores subjetivos y, por otra, a avanzar diversas propuestas para la reducción de la siniestralidad y la morbilidad en el trabajo de conducción.

\section{LA SINIESTRALIDAD EN CARRETERA EN ESPAÑA}

\section{La siniestralidad en carretera en España}

La ponencia inaugural, realizada por el Prof. Dr. Javier Fernández-Costales Muñiz, puso de manifiesto como el problema de la siniestralidad en carretera en nuestro país 
es una cuestión largo tiempo debatida y controvertida en la cual interactúan diferentes y numerosos aspectos.

Sus causas, consecuencias y medidas preventivas han sido a lo largo de los años cuestión de análisis, investigación, discusión e, incluso, enfrentamiento entre los diversos actores implicados.

A lo largo de la exposición se analizaron causas como los límites de velocidad, el estado de las carreteras, de los vehículos, la actitud de los conductores, el alcohol y las drogas, etc...

Esta ponencia realizó un recorrido por todos los aspectos básicos de esta materia: autoridades y entidades responsables, los límites de velocidad, la normativa, el Ministerio de Fomento y el estado de las carreteras, el alcohol y drogas, la señalización de las carreteras, los motoristas, la responsabilidad y experiencia del conductor, medidas frente a la siniestralidad, la educación vial...

\section{Legislación sobre circulación por carretera (mesa redonda)}

Tras la ponencia inaugural, se celebró la primera de las mesas redondas de la tarde, dedicada a definir el marco jurídico aplicable a la circulación de vehículos. Intervinieron en la misma el Prof. Dr. Tomás Alberto Quintana López, la Profra. Dra. Isabel Durán Seco y la Profra. Dra. Elena Pérez Carrillo.

\subsection{Marco jurídico general y régimen administrativo sancionador}

La primera intervención corrió a cargo del Prof. Dr. Tomás Alberto Quintana López, quien comenzó efectuando la oportuna referencia al marco jurídico que rige la circulación por carretera. A este respecto, dejo claro que, antes de conocer qué normas integran el marco jurídico general en materia de circulación por carretera hay que tener en cuenta el reparto de competencias entre el Estado y las Comunidades Autónomas que contienen los artículos 148 y 149 de la Constitución, pues particularmente el artículo 149 en su función de reservar determinadas materias a la competencia exclusiva del Estado, en su apartado 1, regla 21, atribuye a este la competencia exclusiva en las materia de tráfico y circulación de vehículos a motor. Consecuentemente, el marco jurídico aplicable a estas materias lo integran normas aprobadas por el legislador estatal en ejercicio de las competencias reservadas al Estado por el citado artículo 149.1.21 de la Constitución.

Concretamente, de forma principal son las siguientes normas: el Real Decreto Legislativo 6/2015, de 30 de octubre, por el que se aprueba el texto refundido de la Ley sobre Tráfico, Circulación de Vehículos a Motor y Seguridad Vial; el Real Decreto 1428/2003, de 21 de noviembre, por el que se aprueba el Reglamento General de Circulación; el Real Decreto 818/2009, de 8 de mayo, por el que se aprueba el Reglamento General de Conductores y el Real Decreto 2822/1998, de 23 de diciembre, por el que se aprueba el Reglamento General de Vehículos 
Como se ha podido advertir, la regulación de la materia de tráfico está integrada por normas diferentes que afectan a cuestiones diversas, siendo destacables tres: circulación, conductores y vehículos. El cumplimiento de estas normas por parte de los ciudadanos y demás sujetos obligados por las normas de tráfico se halla reforzada por un específico régimen sancionador, cuya regulación se halla en los artículos 74 a 113 del texto refundido de la Ley sobre Tráfico, Circulación de Vehículos a Motor y Seguridad Vial; régimen sancionador en el que deben distinguirse como partes integrantes las siguientes:

1. Los tipos de infracciones, que pueden ser leves, graves y muy graves (arts. 75-77).

2. Las sanciones que se pueden imponer por la comisión de las conductas tipificadas como infracciones son las multas previstas en el artículo $80.1 \mathrm{y}$ graduadas por el artículo 81; cuyas cuantías son diferentes en función de que se trate de infracciones leves, graves o muy graves. En el caso de algunos tipos de infracción, además de la multa que corresponda se podrá imponer como sanción la suspensión de la autorización para conducir por un periodo de hasta un año. Asimismo, la comisión de determinadas infracciones, cuando sean objeto de sanción en firme mediante la imposición de la multa que corresponda, se castigará también con la pérdida de puntos, en los términos previstos en los anexos II (infracciones que llevan aparejada la pérdida de puntos) y IV (cuadro de sanciones y puntos por exceso de velocidad).

3. Responsabilidad. Como regla general será sujeto responsable el autor del hecho en que consista la infracción. No obstante, esta regla tiene excepciones que permiten la imposición de la sanción a un sujeto distinto al autor del hecho (art. 82).

4. Procedimiento sancionador. Se halla regulado en los artículos 83 a 96, sin perjuicio de la aplicación supletoria de la Ley 39/2015, de 1 de octubre, del Procedimiento Administrativo Común de las Administraciones Públicas. En relación con el procedimiento sancionador en materia de tráfico cabe destacar los siguientes extremos:

a. Garantía de procedimiento. No podrá imponerse ninguna sanción en materia de tráfico (en puridad, en ninguna materia) sin la tramitación del correspondiente procedimiento administrativo (art. 83). No caben, pues, las sanciones de plano.

b. Competencia para sancionar. Corresponde a los jefes de tráfico de cada provincia sancionar las infracciones que se cometan en vías interurbanas y travesías; y a los alcaldes las infracciones que se cometan en vías urbanas (art. 84).

c. Principio non bis idem. Cuando en un procedimiento sancionador en materia de tráfico se pongan de manifiesto indicios de que se ha cometido un delito, el órgano que lo esté tramitando lo habrá de paralizar y poner en conocimiento del Ministerio Fiscal los hechos para la depuración de las responsabilidades penales (art. 85).

d. Incoación del procedimiento sancionador. Como regla general, la incoación o inicio del procedimiento sancionador se acordará por la autoridad administrativa competente cuando tenga conocimiento de hechos tipificados como infracción administrativa, bien por iniciativa propia o mediante denuncia, sea ésta realizada por los agentes de la autoridad en materia de 
tráfico o bien por cualquier persona que haya tenido conocimiento de los hechos (art. 86).

e. Las denuncias formuladas por los agentes de la autoridad en materia de tráfico tienen valor probatorio iuris tantum de veracidad. Las denuncias formuladas por los agentes de la autoridad encargados de la vigilancia del tráfico en el ejercicio de las funciones que tienen encomendadas tendrán valor probatorio, salvo prueba en contrario, de los hechos denunciados, de la identidad de quienes los hubieran cometido y, en su caso, de la notificación de la denuncia, sin perjuicio del deber de aquellos de aportar todos los elementos probatorios que sea posible sobre el hecho denunciado (art. 88).

f. Notificación de las denuncias formuladas por los agentes de la autoridad en materia de tráfico. Como regla general, las denuncias se notificarán en el acto al denunciado, en cuyo caso la denuncia notificada en el acto al denunciado supondrá el inicio del procedimiento sancionador. No obstante, la denuncia podrá ser notificada posteriormente cuando concurra alguna circunstancia que impida la notificación de la misma al denunciado en el acto (art. 89), en cuyo caso se practicará dicha notificación según prevén los artículos 90 y 91 .

g. Clases de procedimientos sancionadores: de un lado, el abreviado (requiere que, notificada la multa, el responsable de la infracción proceda al pago de la multa dentro de los veinte días naturales siguientes); de otro el ordinario (cuando el presunto infranctor no haya efectuado el abono voluntario de la sanción, en cuyo caso la instrucción del procedimiento incluye los trámites de alegaciones, prueba, propuesta de resolución y resolución del procedimiento). Para el supuesto de que el sujeto responsable no abone voluntariamente la multa ni tampoco formule alegaciones frente a la denuncia, cuando se trate de infracciones leves, de infracciones graves que no supongan la detracción de puntos, o de infracciones muy graves y graves cuya notificación se efectuase en el acto de la denuncia, la notificación de la denuncia surtirá el efecto de acto resolutorio del procedimiento sancionador.

h. Recurribilidad en vía administrativa de las resoluciones de los procedimientos sancionadores en materia de tráfico. Contra las resoluciones sancionadoras podrá interponerse recurso de reposición, con carácter potestativo, en el plazo de un mes contado desde el día siguiente al de su notificación ante el órgano que dictó la resolución sancionadora, que será el competente para resolverlo. La interposición del recurso de reposición no suspenderá la ejecución del acto impugnado ni la de la sanción. El recurso de reposición se entenderá desestimado si no recae resolución expresa en el plazo de un mes (silencio negativo), quedando expedita la vía contenciosoadministrativa (art. 96).

i. Recurribilidad de las sanciones en vía contencioso-administrativa. Las sanciones administrativas impuestas en materia de tráfico serán recurribles ante la jurisdicción contencioso-administrativa, ante los juzgados de lo contencioso-administrativo. 


\subsection{Legislación sobre circulación por carretera: responsabilidad penal}

La descripción del marco sancionador encontró continuidad en la intervención de la Profra. Dr. Isabel Durán Seco, cuya intervención giró en torno a los aspectos siguientes:

1. La protección penal de la seguridad vial. Problema social de gran importancia que lleva a que los casos más graves se solventen en la vía penal. El Código Penal tipifica delitos contra la seguridad vial (arts. 379 a 385 ter) en los que protege la seguridad vial.

2. Tipos delictivos:

A) Delito de conducción a velocidad excesiva o bajo la influencia de bebidas alcohólicas. Art. 379 CP. De un lado, conducción a velocidad excesiva (conducir un vehículo a motor o ciclomotor en vías públicas superando la velocidad permitida reglamentariamente en $60 \mathrm{~km} / \mathrm{h}$ vía urbana o $80 \mathrm{~km} / \mathrm{h}$ en vía interurbana; ha de diferenciarse de la simple infracción administrativa); de otro, conducir bajo la influencia de alcohol o drogas ( $\mathrm{Se}$ presume la influencia cuando se supere una tasa de alcohol en aire expirado de 0,60 , o una tasa de alcohol en sangre superior a 1,3 grs./l; también se puede cometer el tipo sin superar esas tasas).

B) Conducción temeraria. Art. 380 CP. Supone conducir un vehículo a motor o ciclomotor con temeridad manifiesta y poner en concreto peligro la vida o la integridad de las personas. Será manifiestamente temeraria la conducción (presunción iuris et de iure) si se supera la velocidad y la tasa de alcohol a la que alude el art. 379 CP.

C) Conducción temeraria con manifiesto desprecio por la vida de los demás. Art. $381 \mathrm{CP}$. Comete esta modalidad el que realice la conducción temeraria con manifiesto desprecio por la vida de los demás.

D) Negativa a someterse a las pruebas de alcoholemia y drogas. Art. $383 \mathrm{CP}$. Se castiga la mera negativa a la comprobación de las tasas de alcohol y la presencia de determinadas sustancias. Se cuestionó su constitucionalidad.

E) Conducir sin permiso o licencia. Art. 384 CP. Se castiga la conducción con pérdida de vigencia del permiso o licencia por pérdida total de los puntos asignados legalmente, o por haber sido privado cautelar o definitivamente del permiso o licencia por decisión judicial, o por conducir sin haber obtenido nunca permiso o licencia.

F) Otras alteraciones de la seguridad vial. Art. 385 CP. Se castiga al que ocasione un grave riesgo para la circulación colocando en la vía obstáculos imprevisibles, derramando sustancias deslizantes o inflamables o mutando, sustrayendo o anulando la señalización o por cualquier otro medio. También al que no restablezca la seguridad de la vía cuando haya obligación de hacerlo.

3. Relaciones concursales. Cuando con los actos sancionados en los arts. 379, 380 y 381 CP se ocasionaré, además del riesgo prevenido, un resultado lesivo, se debe apreciar sólo la infracción más gravemente penada, aplicando la pena en su mitad superior, condenando, en todo caso, al resarcimiento de la responsabilidad civil que se hubiera originado.

4. El comiso del vehículo. Art. 385 bis CP. 
5. Reducción en grado de la pena por menor entidad del riesgo causado y demás circunstancias del hecho. Art. 385 ter CP.

\subsection{Legislación sobre seguros}

La Profra. Dra. Elena Fátima Pérez Carrillo puso de manifiesto cómo hablar de la legislación de seguros en el contexto de esta jornada sobre siniestralidad laboral y transporte por carretera plantea un reto arduo. Obliga a moverse entre ámbitos normativos distintos: el asegurador, con su componente de derecho privado, pero también público; el de responsabilidad civil; el de regulación de la circulación, el tráfico y los transportes, por lo menos. Todo ello principalmente en el orden competencial del Estado, que en este sector está intensamente influido por el de la Unión Europea, a través de las Directivas armonizadoras de seguros de vehículos a motor, pero también en relación con derechos de los usuarios (por ejemplo, en el transporte de viajeros por autobús). Y, sin olvidar la concurrencia de normativa autonómica (como en relación con el transporte interurbano).

Existen, junto con coberturas - seguros- obligatorias generales (automóvil, viajeros de servicio público) y específicas (transportes de mercancías peligrosas, de materiales nucleares, o de transportes especiales como el escolar o el sanitario), la incidencia de ramos de seguros que operan mediante pólizas de suscripción voluntaria; coberturas subsidiarias y accesorias.

En el caso de los seguros obligatorios de vehículos a motor (SOVM), el concepto legal central - matizado por la jurisprudencia- es el "hecho de la circulación". También, ciertas coberturas exigidas como requisito para acometer actividades sometidas a autorización administrativa (transporte público, transporte de mercancías peligrosas, etc.).

Aderezando todo ello, cabe subrayar que la regulación de estos seguros se orienta primordialmente a la protección de usuarios y clientes, con lo que las coberturas accesorias -voluntarias- cobran especial importancia en el marco de la siniestralidad laboral y de la reparación de las consecuencias de los siniestros que recaigan sobre trabajadores, en tanto que tales.

En consonancia con lo que constituyó objetivo de la intervención, la Dra. Pérez Carrillo expuso con detalle la legislación aplicable en España en materia de seguros en relación con el objeto de las jornadas, clasificada en torno a los bloques siguientes:

1. El Derecho Privado de los Seguros como marco legal general. El Derecho Público y Privado de los Seguros privados constituyen una unidad institucional. La Ley de Contrato de Seguro de 1980 es la norma fundamental de este Derecho Privado de los Seguros, pero no agota la regulación, que se completa con la legislación de ordenación y supervisión de seguros privados, y sus 3 bloques normativos básicos: la Ley 20/2015 de 14 de julio de ordenación, supervisión y solvencia de las entidades aseguradoras y reaseguradoras (LOSSEAR), la Ley 26/2006, de 17 de julio, de Mediación en 
Seguros y Reaseguros Privados, y el Real Decreto Legislativo 7/2004 de Estatuto Legal del Consorcio de Compensación de seguros.

2. Regulación sobre seguros obligatorios. La normativa se clasifica en:

A) Circulación de vehículos de motor por carretera (SOVM). Real Decreto Legislativo 8/2004, de 29 de octubre, por el que se aprueba el texto refundido de la Ley Sobre responsabilidad civil y seguro en la circulación de vehículos a motor y Real Decreto 1507/2008 por el que se aprueba el Reglamento del Seguro Obligatorio de Responsabilidad Civil de la Circulación de Vehículos a Motor.

B) Seguro Obligatorio de Viajeros (SOV). Real Decreto 1575/1989, de 22 de diciembre, por el que se aprueba el Reglamento del Seguro Obligatorio de Viajeros para transporte público.

C) Seguros obligatorios como requisito de autorizaciones para desarrollar ciertas actividades. Real Decreto 443/2001, de 27 de abril, sobre condiciones de seguridad en el transporte escolar y de menores; Orden PRE/1435/2013, de 23 de julio, por la que se desarrolla el Reglamento de la Ley de Ordenación de los Transportes Terrestres en materia de transporte sanitario por carretera; Real Decreto 1057/2015, de 20 de noviembre, en relación con el arrendamiento de vehículos con conductor; Orden de 20 de julio de 1995, en materia de arrendamiento de vehículos sin conductor; Real Decreto 2364/1994, de 9 de diciembre, por el que se aprueba el Reglamento de Seguridad Privada. Transporte y distribución de objetos valiosos o peligrosos y explosivos... En fin, respecto al transporte por carretera de materiales relacionados con la energía nuclear, es preciso tener en cuenta la Ley 25/1964, de 29 de abril, de Energía Nuclear; la Ley $12 / 2011$, de 27 de mayo, sobre responsabilidad civil por daños nucleares, y la Ley 22/2011, de 28 de julio, de residuos y suelos contaminados.

D) Seguros obligatorios para siniestros que no son "hechos de la circulación". Así, riesgos derivados de las pruebas deportivas en las que intervengan vehículos a motor, celebrados en circuitos especialmente destinados al efecto o habilitados para dichas pruebas, o riesgos de circulación en pistas de aeropuertos y recintos portuarios.

E) Seguros obligatorios subsidiarios. Operan en exceso de otros. Responden a prolija legislación también autonómica: Agencias de viajes, organizadores de espectáculos, ocio, etc.

3. Seguros voluntarios, coberturas subsidiarias y coberturas especiales:

A) Principales ramos de aseguramiento: daños sufridos por vehículos terrestres, sean o no automóviles, salvo los ferroviarios; responsabilidad civil en vehículos terrestres automóviles (comprendida la responsabilidad del transportista) y responsabilidad civil en general (comprende toda responsabilidad distinta de las mencionadas en los ramos anteriores; en España, los riesgos de circulación suelen excluirse de los seguros, pero de contratarse voluntariamente, se elimina la exclusión).

B) Coberturas subsidiarias, operan en exceso de los seguros obligatorios: "cobertura subsidiaria de Autos" (responsabilidad del empresario en el caso de insuficiencia del seguro de los vehículos de sus empleados en comisiones de servicio de la empresa o alquilados), "cobertura subsidiaria de transportistas de carga general", "cobertura subsidiaria de transportistas 
de mercancía peligrosa", "cobertura subsidiaria de operaciones de carga y descarga", "coberturas de responsabilidad civil Patronal" (responsabilidad civil del empresario que se lea exigida por los trabajadores que dependan de él; también, transporte de trabajadores en bus y accidentes laborales originados en vehículos).

C) Coberturas especiales: riesgos de vehículos que realizan actividades agrarias o industriales cuando circulan pero no por vías públicas, probadores de talleres de reparación, aparcadores de establecimientos comerciales, vigilantes de garajes, otras coberturas especiales, seguros para cubrir el riesgo de pérdida de permiso de conducir (ejemplo, Acuerdo General de Transporte), otros seguros relacionados indirectamente con la siniestralidad (por ejemplo seguros de personas, individuales o colectivos -así, los concertados por el empresario para cubrir el riesgo de salud de sus trabajadores-, derivado de siniestro laboral de accidente por carretera, y por exceso de otras coberturas).

\section{Legislación sobre transporte por carretera (mesa redonda)}

Participaron en esta segunda mesa redonda, dedicada a definir el marco jurídico aplicable a la circulación de vehículos, la Profra. Dra. María Angustias Díaz Gómez; la Profra. Dra. Anabelén Casares Marcos; la Profra. Dra. Aurelia Álvarez Rodríguez y el Prof. Davida Carrizo Aguado.

\subsection{Contrato de transporte}

En relación con el marco jurídico general aplicable al contrato de transporte, la Profra. Dra. María Angustias Díaz Gómez, trató las cuestiones principales, concretadas en lo siguiente:

1. Concepto y características

2. Modalidades

3. Contrato de trasporte terrestres de cosas

a. Normativa aplicable y notas distintivas

i. Elementos personales: porteador, cargador y destinatario

ii. Documentación: la carta de porte

b. Derechos, obligaciones y responsabilidad de las partes

i. Del cargador

ii. Del porteador. Especial referencia a su responsabilidad

iii. Del destinatario

4. Contrato de transporte terrestre de personas

a. Normativa aplicable y características

b. Derechos obligaciones y responsabilidad de las partes

5. A modo de resumen de los derechos de los viajeros

Por cuanto hace a los derechos de los viajeros de autobús y autocar en la Unión Europea, procede estar a lo marcado por el Reglamento (UE) $n^{\circ}$ 181/2011 del Parlamento Europeo y del Consejo de 16 de febrero de 2011 sobre los derechos de los 
viajeros de autobús y autocar, de aplicación desde el 1 de marzo de 2013. Recoge los derechos mínimos para los viajeros de estos servicios en el ámbito de la Unión Europea.

\subsection{Legislación sobre transporte de mercancías y viajeros por carretera}

La Profra. Dra. Anabelén Casares Marcos puso de manifiesto como la actividad del transporte terrestre representa un sector económico fundamental. No en vano, se trata de una herramienta necesaria e indiscutible para la buena marcha de la economía y de la sociedad en general, al permitir no solo la movilidad de las mercancías, en sentido estricto, sino también el tránsito y la circulación de las personas. Precisamente por ello, su normativa reguladora ha experimentado una compleja y rica evolución histórica, a raíz de la que se han ido forjando algunas de las categorías y de los conceptos jurídicos propios del Derecho Administrativo moderno. Así, los de obra pública, concesión de obra pública, servicio público, autorización administrativa, policía administrativa, dominio público, expropiación forzosa, inembargabilidad de ciertos bienes, fijación de tarifas, nacionalización como técnica de intervención, etc.

Un iter marcado, en todo caso, por la tensión y fricción entre dos extremos difíciles de conciliar. De un lado, la férrea creencia de que las necesidades de la sociedad se pueden satisfacer, también en este ámbito concreto, desde el ejercicio en exclusiva de la libre iniciativa privada, sin mediación alguna, por tanto, del sector público. De otro, la firme convicción que entiende, en cambio, irrenunciable la intervención del Estado para la adecuada ordenación de la actividad del transporte terrestre. Ambas posiciones, así como el abanico de enfoques y perspectivas intermedias que cabría adoptar al respecto, se encuentran condicionadas por circunstancias diversas, de índole, asimismo, variada, entre otras, políticas, históricas, económicas, culturales, tecnológicas o sociales.

Ahora bien, no cabe hablar con propiedad en nuestro ordenamiento jurídico de un único régimen jurídico para el transporte, sino de tantos regímenes como modalidades de transporte existan, abiertos, por lo demás, a la incorporación de especificidades y peculiaridades propias en función del ámbito territorial sobre el que se presten. Su extraordinaria complejidad deriva de la propia dificultad de la materia regulada, de su realidad física y material, así como, en particular, de las dudas planteadas por su entramado normativo y las fórmulas a él conexas para el reparto de competencias en la materia entre Estado, Comunidades Autónomas y Administraciones locales.

La concreción de esta distribución competencial se revela una labor particularmente farragosa a raíz de las distorsiones y dificultades que introducen en su seno los traspasos, tanto pre- como posconstitucionales de atribuciones y competencias estatales a las Comunidades Autónomas, la aprobación de la Ley 16/1987, de 30 de julio, de Ordenación de los Transportes Terrestres (en adelante, LOTT) como marco normativo para la regulación de un sistema común de transportes, y la confusa, a la par que polémica, jurisprudencia del Tribunal Constitucional sobre algunas de las cuestiones que habrían de incidir de forma más inmediata y directa en la articulación de este reparto competencial. 
En todo caso, pese a la mayor repercusión a estos efectos del reparto competencial entre Estado y Comunidades Autónomas, por cuanto se dilucida, al amparo de los preceptos constitucionales y estatutarios pertinentes, así como de las interpretaciones del Tribunal Constitucional al respecto, la titularidad de las funciones, tanto normativas como ejecutivas, más importantes en relación con el mismo, no debe minusvalorarse en absoluto el papel llamado a desempeñar por las competencias locales en este sector.

Y así, la incidencia de dos conjuntos normativos diversos, con sus dificultades y obstáculos propios, sobre la planificación, establecimiento, articulación, gestión y financiación de este tipo de transportes, esto es, de un lado, la legislación vigente en materia de régimen local, $\mathrm{y}$, de otro, la legislación sectorial aprobada en materia de transportes terrestres, habrá de dotar de especial complejidad al reparto competencial para la regulación y ordenación de los transportes terrestres urbanos.

No en vano, la aprobación del texto constitucional de 1978 abre nuevas expectativas para los transportes terrestres de competencia y ámbito local. Así, la creación de las Comunidades Autónomas y la asunción por estas de importantes competencias normativas en materia de transportes terrestres permite presagiar su importante papel en la articulación de estos transportes de ámbito local como auténtico sistema. Las posibilidades al alcance del legislador autonómico son, en este sentido, innumerables, no solo por su competencia exclusiva en materia de transportes terrestres intraautonómicos, sino también por las competencias de desarrollo que le corresponden en materia de régimen local.

\subsection{Legislación sobre transporte internacional de viajeros}

La exposición de la Profra. Dra. Aurelia Álvarez Rodríguez versó sobre el Derecho del transporte internacional, sector del ordenamiento jurídico de vital importancia. Ahora bien, la diversidad normativa existente de acuerdo con el medio de transporte usado para desplazarse de un país a otro Estado presenta excesiva complejidad. Y a ello procede añadir la fuerte vinculación a la soberanía de los Estados en el ejercicio de control y vigilancia de las fronteras. Sin duda, el transporte de personas de carácter internacional se caracteriza por los derechos y deberes impuestos tanto a los usuarios del medio de transporte como a los propios transportistas; ello sin olvidar las eventuales responsabilidades que se derivan por la ausencia de un correcto cumplimiento del contrato o por el acaecimiento de un accidente durante el transcurso del viaje.

En concreto, en materia de pasajeros, el objetivo del transporte es conseguir que éstos junto con sus equipajes lleguen al destino contratado a la hora prevista y sin sufrir ningún percance.

Antes de iniciar el estudio de los diferentes tipos los contratos internacionales de transporte de pasajeros es preciso efectuar una precisión: aunque pertenecen esencialmente al ámbito del Derecho privado, el Derecho público representa un papel importante, ya que la soberanía del Estado implica una potestad en el control de sus fronteras -aeropuertos, puertos, fronteras terrestres ${ }^{-}$. A ello deben añadirse las 
obligaciones adquiridas tanto por los transportistas como por los pasajeros en los diversos medios de locomoción existentes.

A la hora de proceder al estudio y análisis de los contratos internacionales de transporte de pasajeros, es preciso distinguir transporte aéreo, transporte marítimo y transporte terrestre: transporte por ferrocarril, autobús o autocar y automóviles.

En lo que concierne al transporte terrestre por carretera en autobús o/y autocar la norma fundamental es el Reglamento (UE) núm. 181/2011 del Parlamento Europeo y del Consejo, de 16 de febrero de 2011, sobre los derechos de los viajeros de autobús y autocar y por el que se modifica el Reglamento (CE) núm. 2006/2004.

A los transportistas corresponde velar porque los pasajeros puedan acceder al territorio del Estado de destino. Si bien es cierto que en las cláusulas de los contratos se inserta entre los requisitos la necesidad de aportar la documentación válida y vigente. Los pasajeros deben estar en posesión de la documentación requerida para el traspaso de fronteras. En el caso de un viaje desde fuera del territorio Schengen, en el cruce por un puesto fronterizo, los pasajeros deberán cumplir los requisitos establecidos en el art. 6 del Reglamento (UE) 2016/399 del Parlamento Europeo y del Consejo, de 9 de marzo de 2016, por el que se establece un Código de normas de la Unión para el cruce de personas por las fronteras (Código de fronteras Schengen). En el mencionado precepto se alude a los documentos de viaje impuestos. La necesidad o no del visado se encuentra regulado específicamente en el Reglamento (CE) núm. 539/2001 del Consejo de 15 de marzo de 2001 por el que se establecen la lista de terceros países cuyos nacionales están sometidos a la obligación de visado para cruzar las fronteras exteriores y la lista de terceros países cuyos nacionales están exentos de esa obligación; por su parte, aquellos pasajeros que precisen un visado deben solicitarlo de acuerdo con lo previsto en el Reglamento (CE) núm. 810/2009 del Parlamento Europeo y del Consejo de 13 de julio de 2009 por el que se establece un Código comunitario sobre visados (Código de visados).

Por su parte, las obligaciones de los transportistas internacionales se encuentran recogidas en dos textos: la Directiva 2001/51/CE del Consejo, de 28 de junio de 2001, por la que se completan las disposiciones del artículo 26 del Convenio de aplicación del Acuerdo de Schengen de 14 de junio de 1985. En el articulado de esta directiva impone que "los Estados miembros adoptarán las disposiciones necesarias para garantizar que la obligación de los transportistas de devolver al lugar de procedencia a los nacionales de terceros países prevista por las disposiciones de la letra a) del apartado 1 del artículo 26 del Convenio de Schengen se aplique, asimismo, cuando se deniegue la entrada a un nacional de un país tercero en tránsito si: a) el transportista que debía trasladarlo a su país de destino se negara a embarcarlo, o si b) las autoridades del Estado de destino le hubieran denegado la entrada y lo hubieran devuelto al Estado miembro por el que ha transitado" (art. 2). Por otra parte, los transportistas deben comunicar los datos de las personas transportadas (Directiva 2004/82/CE del Consejo de 29 de abril de 2004). 


\subsection{Legislación sobre transporte internacional de mercancías}

No cabe duda, según indicó el Prof. David Carrizo Aguado, que el Derecho del transporte es una pieza esencial en el progreso del comercio internacional bajo un sistema de mercado transnacional y de economía globalizada. El transporte de personas y mercancías es la operación económica más necesaria e imprescindible que conlleva antes o después un desplazamiento.

En concreto, en materia de mercancías, el objetivo del transporte es conseguir que las mismas lleguen a un determinado destino en el cual su valor relativo es más alto que en origen. Para que tal finalidad beneficie tanto al productor, fabricante $o$ comercializador, estos operadores deben implicarse en el transporte, dominar todos sus aspectos y perseguir ventajas de control del mismo.

El mercado y la competencia tienden a una dimensión mundial del comercio y las empresas están orientadas a tal sentido. En esta tesitura la logística es de suma importancia, pues en todo momento es preciso comprender, controlar y optimizar el flujo de mercaderías e información desde el origen hasta el destino. Además, es necesario conocer las características de cada uno de los medios que pueden utilizarse para llevarlo a cabo.

Desde un primer momento, tenemos que tener presente que los contratos de transporte de mercaderías pertenecen esencialmente al ámbito del Derecho privado y no al del Derecho público y en todo caso nunca serán contratos de consumo. En la actualidad, todos los contratos de transporte se celebran entre partes comerciales, con un poder de transacción similar, a pesar de que los cargadores de gran escala poseen un poder de negociación muy considerable.

Un dato que debe distinguirse, es que, en la última veintena de años, los gobiernos no se están haciendo cargo de las empresas de transporte, pues es un sector que no queda comprendido en el marco de la noción de transporte como servicio público de interés general. A consecuencia de ello, el transporte se ha ido transfiriendo desde la esfera pública de los transportes por la dinámica de la libre competencia, tanto nacional como internacional, entre intereses comerciales privados. Pues ello se observa con nitidez en la privatización de aeropuertos, control de tráfico externo, puertos, terminales, servicios portuarios, etc.

La importancia práctica del transporte ha originado que su regulación se encuentre altamente estandarizada. La universalidad de la regulación material del transporte internacional es una de las características más destacadas en este sector. Dentro de las transacciones internacionales, el transporte es uno de los sectores donde más se ha experimentado la necesidad de construir normas uniformes que se superpongan al particularismo existente en las legislaciones nacionales y que ofrezcan mayor seguridad jurídica a los empresarios en sus relaciones privadas. Así, el Derecho de los transportes se ha desarrollado en función de sus propias necesidades y de los progresos tecnológicos. 
Una de las cuestiones principales en la reglamentación de los transportes es la internacionalidad a través de normas materiales de carácter uniforme y no de normas de conflicto de origen internacional.

En el estudio de la regulación del transporte internacional se ha de tener en cuenta la necesaria interrelación entre la normativa convencional, el derecho autónomo de cada Estado y la autorregulación de los intervinientes en el tráfico. De la articulación de estas diversas reglas se desprende una normativización que se ocupa de los diferentes problemas que derivados de una determinada operación de transporte. En concreto cuáles son las obligaciones de cada uno de los intervinientes, si se trata de una obligación de medios o de resultados, si la responsabilidad es objetiva o solamente opera cuando se muestra que ha existido culpa en el cumplimiento de la obligación, también la legitimación activa y pasiva en los litigios que se deriven de operaciones de transporte, así como la documentación precisa en dichos contratos.

A la hora de proceder al estudio y análisis de los contratos internacionales de transporte de mercancías, se alude a la siguiente diferenciación: transporte marítimo, transporte aéreo, transporte por carretera y transporte por ferrocarril. En lo que concierne al transporte de mercaderías por carretera, está regulado por el Convenio de Ginebra de 19 de mayo de 1956, del cual España forma parte desde 1974. Éste texto tiene por propósito la uniformidad en la regulación del contrato de transporte internacional de mercaderías, prestando particular atención a los documentos utilizados en este tipo de transporte y a la responsabilidad del transportista.

\section{LA SINIESTRALIDAD Y MORBILIDAD LABORAL EN CARRETERA}

\section{El riesgo de accidente laboral en la conducción profesional. Especial referencia al transporte (autónomo o por cuenta ajena) por carretera}

La primera ponencia de la tarde corrió a cargo de la Profra. Dra. $\mathrm{M}^{\mathrm{a}}$ de los Reyes Martínez Barroso, cuya intervención comenzó constatando como a nadie puede extrañar que el accidente de tráfico tipo se convierta en un riesgo profesional (accidente de trabajo) para los profesionales de la conducción y que esta contingencia profesional pueda tener una mayor o menor cobertura dependiendo de que dicho profesional tenga la condición de trabajador autónomo o trabajador por cuenta ajena.

Las reflexiones posteriores giraron en torno a un suceso real, objeto de litigio ante la Sala de lo Contencioso-Administrativo del Tribunal Superior de Justicia de Murcia, de 29 de enero de 2016 (Rec. núm. 174 /2015). La exposición comenzó con la descripción del marco regulador de referencia en los actos de encuadramiento y orden jurisdiccional competente para su revisión, tras lo cual se expuso la cuestión controvertida.

El supuesto de hecho sobre el que versa la sentencia controvertida está referido al alta de oficio en el Régimen General de la Seguridad Social, de D. Bienvenido, como trabajador de la empresa "Taxistas Reunidos. S.L.", con efectos de 8 de noviembre de 
2014, y la baja con efectos de la misma fecha, llevada a cabo por Resolución de la Dirección provincial de la Tesorería General de la Seguridad Social de Murcia, de 27 de febrero de 2015, desestimatoria del recurso de alzada formulado contra resolución de 14 de diciembre anterior sobre reconocimiento de alta en el Régimen General de la Seguridad Social de dicho profesional.

En dicha resolución administrativa se argumenta la procedencia del alta, al haberse constatado por la Inspección de Trabajo y Seguridad "la prestación de servicios por el trabajador para dicha empresa" el día 8 de noviembre de 2014, en principio, y a pesar de los escasos datos de la sentencia, con ausencia de autonomía y sin asumir el riesgo del negocio.

La pretensión deducida en el recurso contencioso administrativo es que se dicte sentencia por la que se anulen las resoluciones impugnadas (tanto la de alta como la desestimatoria del recurso de alzada), con imposición de costas a la Administración demandada. Y se impugnan alegando la parte actora "que el artículo 145 de la Ley de Procedimiento Laboral impide a las Entidades Gestoras y Servicios Comunes de la Seguridad Social revisar, por sí mismos, los actos declarativos de derechos en perjuicio de los beneficiarios, debiendo formular ante el Juzgado de lo Social competente la oportuna demanda, que se dirigirá contra el beneficiario del derecho reconocido". Vaya por delante la sorpresa que provoca que la parte demandante siga haciendo referencia a la vieja Ley de Procedimiento Laboral en lugar de a la correspondiente Ley reguladora de la Jurisdicción Social, dados los años transcurridos desde su entrada en vigor.

Como cuestión previa, y en cuanto a la cuantía del recurso, se desestima la alegación de la parte actora de que es 42,91 €, pues según establece el art. 42.2 de la Ley 29/1998, de 13 de julio, reguladora de la jurisdicción Contencioso-administrativa, se reputarán de cuantía indeterminada los recursos interpuestos contra actos, en materia de Seguridad Social, que tengan por objeto la inscripción de empresas, formalización de la protección frente a riesgos profesionales, tarifación, cobertura de la prestación de incapacidad temporal, afiliación, alta, baja y variaciones de datos de trabajadores.

En cuanto al fondo, la empresa recurrente alega que la "relación que unía a las partes era de carácter mercantil", siendo el trabajador autónomo y la relación muy esporádica, mientras que en el informe de la Inspección de Trabajo se hacen constar las circunstancias que, a su juicio, determinan el carácter laboral de la relación, concretamente que la empresa concertó de forma verbal con la parroquia Nuestra Señora del Rosario, de Bullas, el viaje Bullas-Alcalá de Henares-Madrid-Bullas, a realizar el día 8 de noviembre de 2014. El viaje se hizo en el autobús Volvo... matrícula... JJD, realizando la conducción D. Indalecio y D. Bienvenido, a quien contrató "Taxistas Reunidos, S.L." para dicho viaje como conductor a fin de cumplir lo establecido en cuanto a jornada, horarios y tiempo de descanso de D. Indalecio. Según manifestaciones de D. Bienvenido, en el viaje de vuelta conducían ambos, y poco antes de hacer parada en Honrubia, D. Indalecio "le ordenó" que a partir de dicha parada y hasta Bullas debía conducir otro autobús, propiedad de la empresa José Ruiz Campos, que había sido subcontratada por la recurrente para el citado viaje, para que el conductor de dicho autobús, D. Pascual, pudiera cumplir con los tiempos de 
conducción y descanso. D. Indalecio conducía dicho autobús, sufriendo accidente de tráfico al tomar el desvío hacia Calasparra, desde la carretera de Madrid.

La parte demandada se opone al recurso, alegando la presunción de certeza de las actas de la Inspección de trabajo, y remitiéndose a las conclusiones obtenidas por esta, desestimando la Sala de lo Contencioso el recurso interpuesto, con imposición de las costas a la parte actora en virtud de lo dispuesto en el art. 139.1 de la Ley 29/1998. Contra dicha sentencia no cabe recurso ordinario alguno.

Las claves de la posición jurisprudencial mantenida en la sentencia en orden a delimitar el carácter mercantil o laboral del vínculo entre el conductor y la empresa son fundamentalmente las siguientes: pese a que la parte actora alega que la relación era "esporádica" y la contratación "mercantil" entre dos empresas, sin embargo, el principal argumento que utiliza la Sala de lo Contencioso-Administrativo del Tribunal Superior de Justicia de Murcia es que "la no habitualidad de la prestación no impide que tenga naturaleza laboral", como sucede en este caso, en que el servicio se presta en "el ámbito de la dirección y organización de una empresa, y con los medios materiales de esta".

Es más, dado que en la tramitación del procedimiento judicial la recurrente no ha practicado ninguna prueba tendente a desvirtuar los hechos alegados por la Inspección de Trabajo, como pudiera ser la factura girada por la prestación de tales servicios, el órgano juzgador llega a la conclusión de que "ante la presunción de certeza de las actas de la Inspección de Trabajo" al no existir prueba alguna de la contratación mercantil, se concluye que la relación era laboral y por ello resultaba procedente el alta del trabajador en el Régimen General de la Seguridad Social, sin perjuicio de que ya estuviera en alta como autónomo por los trabajos que pudiera realizar por cuenta propia. Esto es, se centra la solución del caso en la presunción de veracidad de la que deben de gozar las actas de la Inspección, así como en su valor y fuerza probatoria, sabiendo que las mismas han de constituir una presunción iuris tantum, por lo que se desplaza la carga de la prueba a quien perjudica, conforme a los establecido en la STSJ País Vasco, 21 octubre 2014 (Rec. núm. 1806/2014).

Así las cosas, es imposible desconocer que la línea divisoria entre el contrato de trabajo y otros vínculos de naturaleza análoga, regulados por la legislación civil, o mercantil, en su caso, no aparece nítida, ni en la doctrina científica y jurisprudencial, ni en la legislación, y ni siquiera en la realidad social, pues cuando se trata de calificar la relación jurídica que vincula a las partes litigantes, para decidir si en ella concurren las notas definitorias de la laboral, previstas en el art. 1 ET, es necesario tomar en consideración la totalidad de las circunstancias concurrentes en el caso, con el fin de constatar si se dan las notas de ajenidad, retribución y dependencia en el sentido en que son concebidas por la jurisprudencia sobre la calificación del contrato en virtud del cual se prestan unos servicios, que con el mismo contenido, pueden derivarse de un contrato de trabajo o de un arrendamiento de servicios, o de un contrato de transporte, siendo indiferente la denominación que los interesados hubieren dado a su contrato. 
En definitiva, se trata de dilucidar en qué medida la prestación del servicio se está realizando bajo dichas notas específicas, a tenor de las circunstancias concurrentes en el caso concreto o lo que la jurisprudencia y doctrina judicial entiende como "indicios" comunes de ajenidad (las decisiones de mercado y de precios las toma el empresario, la remuneración tiene un carácter fijo o periódico y siempre en proporción con la actividad prestada, el riesgo de la actividad es asumida por el empresario, etc.) y dependencia (el trabajo se presta en el centro del empresario o lugar designado por éste, las instrucciones y procedimientos a seguir también las proporciona el empresario, los horarios y la actividad están previamente programados, etc.). No obstante, este es quizás el aspecto menos elaborado en la sentencia analizada, pues se echa en falta un estudio más pormenorizado de los elementos típicos de la relación laboral.

Probablemente la omisión sea consecuencia de los muchos indicios, reiterados en otros muchos pronunciamientos de las Salas de lo Social, que provocan que la Sala de lo Contencioso-Administrativo centre su argumentación en un problema menos evidente (cuál es la frontera entre esporádico o habitual) pasando casi sin detenimiento por este elemento nuclear a partir de la presunción de certeza del acta de la Inspección de Trabajo (máxime teniendo en cuenta que la empresa recurrente ni siquiera intentó probar lo contrario). En fin, la consolidación de una realidad, como la que evidencia la sentencia comentada, de prestación de servicios en régimen de falsa autonomía, no puede hacer olvidar a quien aplica el derecho la subsistencia de un concepto, como el de trabajador por cuenta ajena, aplicable más allá de la existencia de meros datos formales, como el alta en el RETA. Y que, en este supuesto, como en otros similares que han llegado a los Tribunales la Tesorería actúa, no para la determinación de la laboralidad, sino en el contexto del cumplimiento de las obligaciones derivadas de la realidad constatada y para garantizar los derechos de las personas incluidas en el ámbito subjetivo de los regímenes de la misma. En definitiva, el camino para discernir los límites de la laboralidad es a través de la impugnación del acta de la Inspección.

\section{Los conductores "no profesionales": accidentes in itinere y en misión}

La ponencia corrió a cargo del Prof. Dr. Rodrigo Tascón López, quien partió de un dato incontestable, cual es que un porcentaje muy significativo de los accidentes de circulación que se producen en España (que puede ser cifrado en un intuitivo y aproximativo $2 / 3$ del total) son sufridos por personas que, en ese preciso momento, o se desplazaban hacia su trabajo (accidente in itinere) o estaban ya trabajando (conductores profesionales - de los que se ocuparán con todo detalle otras ponenciaso accidente en misión).

Sin duda, esta evidente realidad debe hacer que se replantee desde distintos puntos de vista la actuación jurídica, administrativo e institucional que merece una situación tan ciertamente peligrosa y potencialmente dañina, capaz de producir costes sociales y personales altísimos para las posibles víctimas. 
Así, de un lado, la conducción habría de ser considerada de forma habitual un riesgo profesional evaluable y prevenible al que se dedicara mucha mayor atención en los protocolos preventivos. Desde luego, siempre que los trabajadores tuvieran que conducir, ya fuera de forma habitual, ya esporádicamente, de forma potencial, es conveniente que sea incorporado entre los riesgos profesionales de los trabajadores y se traten de adoptar las medidas preventivas destinadas a evitar los posibles accidentes (cursos de conducción segura, adecuada explicación de cómo funcionan los vehículos de la empresa...).

De hecho, la presencia de este riesgo "de conducción de vehículos a motor", unido a la ausencia de cualquier medida preventiva o formativa por parte de la empresa, hace que algunos pronunciamientos de los tribunales hayan considerado la existencia de negligencia por parte de la empresa, lo que tiene su relevancia a la hora de ponderar las consecuencias de dicho accidente, ya en forma de recargo de prestaciones, ya en forma de indemnización de daños y perjuicios para el trabajador.

Igualmente, el hecho de que, normalmente (y salvo excepciones) el trabajador tenga que desplazarse desde su domicilio hasta el centro de trabajo, debiera llevar a la empresa a adoptar una política preventiva al respecto. Fuera a través a través de formación específica en el ámbito de la conducción (cuando no quede otro remedio y los trabajadores acudan a la empresa en vehículo particular), fuera a través de la implantación de una política de transporte colectivo de empresa o del fomento (y financiación) del transporte público.

De otro, el enfoque a la protección social que el accidentado merece, debiera ser ponderado a la luz de las circunstancias actuales, cosa que, como se verá, los tribunales ya están haciendo de forma lenta, pero satisfactoria. Como es obvio, para el trabajador perjudicado que su accidente merezca la consideración legal de accidente de trabajo tienen innegables ventajas (mayores cuantías prestacionales, ausencia de requisitos de carencia, principio de automaticidad...) y, por tanto, siempre estará interesado en acreditar que su contingencia ha tenido un claro origen profesional. Deslindando los dos casos en presencia:

1.- El accidente in itinere es el que se produce al ir o volver del lugar de trabajo; la LGSS lo asimila al accidente de trabajo (el ocurrido por ocasión o como consecuencia del trabajo), pero, en cambio, no resulta de aplicación la presunción de laboralidad (que supone como de trabajo todo accidente ocurrido en tiempo y lugar de trabajo), lo que hace que sea el trabajador el que deba acreditar los extremos relativos al accidente y su carácter de desplazamiento laboral, y dificulta en gran medida la prueba de algunos de ellos, como, por ejemplo, en los supuestos de súbitos episodios cardíacos (aunque en algún supuesto reciente el Tribunal Supremo ha entendido que se puede considerar accidente de trabajo el infarto o ictus ocurrido durante el trayecto de vuelta a casa si la indisposición ya había comenzado en el centro de trabajo).

Los pronunciamientos de los tribunales laborales habían sido bastante estrictos para considerar que, para merecer la consideración de verdadero accidente de trabajo debía ocurrir en tiempo inmediato o razonablemente próximo a la hora de entrada o salida 
del trabajo siempre que dicho accidente tenga lugar en el trayecto usual desde el domicilio habitual (no, por ejemplo el de la novia o familiar en el que ocasionalmente se hubiera pernoctado), utilizando un medio de transporte adecuado (no uno peligroso o extravagante) y sin desvíos para realizar otras actividades (a no ser que se tratara de actividades ordinarias como llevar a los hijos al colegio; pero, por ejemplo, dar un pequeño rodeo para visitar a tu padre en el pueblo hacía perder al accidente su condición de in itinere; célebre es el caso en el que se negó la laboralidad a un accidente sufrido por un trabajador que viajaba a pasar la nochebuena con su familia para regresar al día siguiente a la localidad donde trabajaba).

Afortunadamente, en los últimos tiempos, los tribunales están relajando un poco tan estricta postura. Dos casos significativos sirven para ilustrar la anterior afirmación: de un lado, la célebre STS 26 de diciembre 2013, en la que se entendió que era accidente in itinere el sufrido por un trabajador en la noche del domingo cuando regresaba desde el domicilio familiar a su domicilio en la localidad donde trabajaba (separadas por unos $350 \mathrm{~km}$ ), de cara a incorporarse a su puesto el lunes por la mañana.

De otro, y también harto ilustrativo, aquel pronunciamiento del TSJ Cataluña 12 de junio 2014 en el que considera como accidente de trabajo el sufrido por un operario que se desplazaba en patinete a su puesto de trabajo, algo que muestra el intento de los tribunales por adaptar conceptos seculares a los nuevos y modernos tiempos que toca vivir.

2.- El accidente en misión es el que sufre un trabajador mientras se está desplazando para cumplir un cometido o tarea profesional encargado por la empresa. El TS ha entendido sin reparos que aquí estamos, no ante una asimilación (como en el caso de accidente in itinere) sino ante un verdadero accidente de trabajo, que se produce en tiempo de trabajo y que, por tanto, merece gozar de la presunción de laboralidad.

Ahora bien, como cabe suponer, la casuística es casi infinita, y sí que es verdad que los tribunales han efectuado algunas precisiones. Por ejemplo, que no es accidente de trabajo aquel que se produce en circunstancias ajenas a la prestación laboral: así, el caso de trabajadores que, tras acabar la tarea sufren un infarto en el hotel donde se alojan, o tienen un percance en una playa a la que han ido, o mientras se toman unas copas (aunque sea con las personas a las que han ido a visitar por motivos profesionales).

Ahora bien, y respecto a los episodios cardíacos, algún pronunciamiento ha entendido que sí puede haber relación de laboralidad si el episodio se produce en un contexto de mucho estrés profesional, aunque sea una vez finalizada la jornada, ya en la habitación del hotel, o, incluso, de regreso en el domicilio del trabajador.

Además, este criterio flexible también se ha seguido para considerar que, aunque el trabajador desplazado no esté trabajando en sentido estricto, cabe entender que ocurre accidente en misión cuando el desplazamiento se haya producido por encargo de la empresa (por ejemplo, para representar a la entidad en el funeral de un antiguo empleado). 
Sea como fuere, resulta un tanto extraño (sobre todo al profano en Derecho) que algo tan importante como la protección social que merece un trabajador, dependa de circunstancias tan aparentemente casuales (casi azarosas) como las que se han descrito. Ello, quizá, se hace especialmente evidente en los supuestos de accidente de circulación (sean in itinere o en misión) y, desde luego, llevan a quien esto trata de explicar a pedir una acción normativa que sistematice y clarifique la situación jurídica de los trabajadores que sufren un percance de tráfico.

\section{Morbilidad en los trabajos de conducción (mesa redonda)}

Participaron en la mesa redonda el Prof. Dr. D. José Gustavo Quirós Hidalgo, la Profra. Dra. Beatriz Agra Viforcos, la Profra. Dra. Natalia Ordóñez Pascua y el Prof. Dr. Juan José Fernández Domínguez.

\subsection{Los trastornos musculoesqueléticos en la conducción y tareas anejas}

La intervención del Prof. Dr. José Gustavo Quirós Hidalgo se estructuró en dos grandes bloques:

1. Riesgos musculoesqueléticos en la conducción. Aun cuando el ámbito de estudio de la Ergonomía resulta, sin duda y conforme de todos es sabido, mucho más extenso, la exposición siguiente vendrá centrada, fundamentalmente, en los factores con incidencia en molestias, patologías, dolencias o trastornos de carácter musculoesquelético, pues otros elementos de confort/disconfort para el conductor de vehículos por carretera, tales como temperatura, humedad, corrientes, calidad del aire, iluminación, vibraciones, ruido, etc, se analizan normalmente como riesgos físicos.

Constitutivas de una lesión ampliamente extendida entre la población, está demostrado que los trastornos musculoesqueléticos se generan fundamentalmente en el ámbito laboral, y aun cuando puedan proceder de traumatismos agudos, normalmente tienen carácter acumulativo como resultado de la exposición a factores de riesgo durante un período prolongado, en ocasiones en conjunción con otras patologías o circunstancias extralaborales.

En el trabajo que exige largos períodos al volante, la columna vertebral es una de las partes más susceptibles de lesión o de molestia; ello no obstante, también pueden aparecer trastornos musculoesqueléticos en el cuello, así como en las extremidades superiores e inferiores, sin perjuicio de otras manifestaciones habituales pero de menor importancia cuantitativa y cualitativa.

El inadecuado diseño del puesto y las malas posturas adoptadas son los motivos principales de estas dolencias. Para el concreto caso de las mujeres, también es factor de mayor peligro el diseño adaptado a la medida masculina de unos espacios de trabajo destinados para el desempeño por hombres. 
En consecuencia, es necesario llevar a cabo actuaciones ergonómicas a partir de una preceptiva evaluación de riesgos. Entre otras medidas a adoptar, la OIT plantea las siguientes: cabinas de conducción bien diseñadas, con asientos plenamente ajustables y mandos adecuadamente dispuestos, coordinación entre los ajustes del asiento y del volante, graduación del tablero de instrumentos, reducción del tamaño del volante mejora las relaciones entre los espacios, asiento regulable y con amortiguación adecuada, optimización del cinturón de seguridad.

Por cuanto hace a la vigilancia de la salud, la experiencia demuestra cómo la columna es una de las partes del cuerpo más dañadas en quienes han de prestar servicios prolongados de conducción. En este sentido la obligación empresarial de vigilancia de la salud (art. 22 LPRL) se muestra como un instrumento indispensable para la detección de las lesiones sufridas (o para identificar el riesgo de que se produzcan) en los profesionales del volante. A este respecto, el protocolo del reconocimiento debería incluir, al menos, el siguiente contenido: exploración laboral del medio y personal del trabajador, antecedentes de exposición, precedentes de salud de interés, historia clínica actual y, finalmente, valoración facultativa individualizada.

Por otra parte, tampoco debe olvidarse la importancia de la formación e información de los conductores (tan comúnmente olvidada o minusvalorada), sobre todo, por cuanto aquí importa, respecto a la necesidad de mantener durante la conducción una postura adecuada, ejercicios de relajación, estiramiento y fortalecimiento muscular y en lo referente al debido respeto a los tiempos de trabajo y descanso.

En definitiva, cuando se manifiestan estos riesgos, lo cual es habitual, el tratamiento y la recuperación suelen ser insatisfactorios, especialmente si la dolencia se ha cronificado, por lo que no es difícil que acaben en incapacidad permanente y pérdida del puesto de trabajo. Precisamente por eso la prevención resulta esencial. En el peor de los casos, el mantenimiento de los trabajadores con trastornos musculares y/o esqueléticos en el trabajo debe formar parte de la política laboral en la materia.

2. Riesgos musculoesquéleticos en tareas anejas: labores de carga y descarga. Casi una quinta parte de los accidentes notificados en el sector tienen lugar durante las labores de carga y descarga, por lo que parece oportuno referirse de forma específica a los riesgos existentes y a las medidas preventivas a observar en las mismas. A tal efecto, también es necesario, de un lado, distinguir entre transporte de viajeros y de mercancías; y de otro, resaltar la importancia adicional de las normas generales sobre seguridad vial y ordenación de los transportes terrestres, que o bien conviven con las preventivas o, en muchos casos, son las únicas a considerar.

Respecto al transporte de personas, son las reglas comunes las que permiten extraer las medidas oportunas, pensadas para la mayor seguridad de los pasajeros pero que redundan también en la del profesional. En este sentido, el Real Decreto 1428/2003, de 21 de noviembre, por el que se aprueba el Reglamento General de Circulación (RGC), regula el número máximo de personas a transportar, límites de peso, las reglas concretas para la seguridad y la evitación de accidentes, referidas tanto al propio conductor como a los pasajeros. Además, existe normativa específica para el transporte escolar y de menores (RD 443/2001) y para personas con discapacidad (RD 
1544/2007), distinguiendo en este caso entre transporte urbano e interurbano, sanitario y autotaxi.

Por cuanto hace al transporte de mercancías, junto a las normas genéricas de circulación y de ordenación del sector con incidencia en el tratamiento de los riesgos existentes en las labores de carga y descarga, resulta aplicable diversa legislación específicamente preventiva en virtud de las actividades a desarrollar y los equipos a utilizar; no obstante, cabe añadir también otras fuentes diversas en función de la mercancía transportada (especialmente para animales, sustancias peligrosas y residuos).

Así, en primer lugar, el RGC regula la carga transportada y los accesorios utilizados para su acondicionamiento o protección, así como las dimensiones permitidas para las mercancías. En segundo término, es preciso tener en cuenta el RD 487/1997, de 14 de abril, sobre disposiciones mínimas de seguridad y salud relativas a la manipulación manual de cargas que entrañe riesgos, en particular dorsolumbares, para los trabajadores, con especial importancia de su Anexo relativo a los factores de riesgo relativos a las características de la carga, el medio de trabajo, el esfuerzo físico necesario, las exigencias de la actividad y los condicionantes individuales. Además, la Guía técnica para la evaluación y prevención de los riesgos relativos a la manipulación manual de cargas ofrece un completo y detallado método para acometer una evaluación adecuada y eficaz. De persistir el riesgo, las medidas vendrán dadas por la utilización de ayudas mecánicas, la reducción o rediseño de la carga, la actuación sobre la organización del trabajo o la mejora del entorno de trabajo.

Por su parte, si la manipulación de la carga está mecanizada, cabe atender adicionalmente al RD 1644/2008, de 10 de octubre, que establece las normas para la comercialización y puesta en servicio de las máquinas, y al RD 1215/1997, de 18 de julio, sobre Disposiciones Mínimas de Seguridad y Salud para la utilización por los trabajadores de los equipos de trabajo, con especial trascendencia de la Guía técnica para la evaluación y prevención de los riesgos relativos a la utilización de los equipos de trabajo. Por cuanto hace especialmente al transporte por carretera, los Anexos de la citada norma se refieren a los requisitos de los equipos de trabajo móviles, automotores o no, y a los equipos de trabajo para elevación de cargas, sometidos a reglas concretas sobre su diseño y utilización. En fin, siendo habitual en el sector del transporte terrestre por carretera y en las operaciones de carga y descarga mecanizadas el uso de aparatos como ascensores, montacargas, escaleras mecánicas, andenes móviles, montamateriales, grúas, aparatos de elevación y transporte continuos, transelevadores, plataformas elevadoras o carretillas de manutención, procede hacer una doble remisión: de un lado, al RD 2291/1985, de 8 de noviembre, por el cual se aprueba el Reglamento de aparatos de elevación y manutención; de otro, a varias Notas Técnicas de Prevención que ofrecen un análisis minucioso sobre formación, instalación, utilización, mantenimiento, riesgos existentes o medidas preventivas de algunos equipo como carretillas elevadoras y grúas puente (con NTP específicas). 


\subsection{Riesgos mecánicos y riesgos derivados del ambiente de trabajo (agentes físicos)}

La charla, a cargo de la Profra. Dra. Beatriz Agra Viforcos, abordó, en primer lugar, los riesgos mecánicos, $\mathrm{y}$, en segundo término, los derivados de agentes físicos.

1. Riesgos mecánicos. El principal es el riesgo de circulación, asociado a tres tipos de factores: relacionados con la vía (heladas, firme en mal estado, trazado...), relacionados con el vehículo siniestrado (averías) o relacionados con el factor humano (distracción, factores emocionales, patologías, intoxicaciones, velocidad...), siendo estos últimos causantes del siniestro en hasta el $90 \%$ de los casos.

Por cuanto hace a las consecuencias de la materialización del riesgo, es decir, del acaecimiento de un siniestro, los daños que pueden afectar a los ocupantes de un vehículo a motor pueden ser, conforme de todos es sabido, muy graves, hasta el punto de poder llegar a provocar la muerte.

En la hipótesis de colisión frontal (entre dos vehículos o de uno contra un objeto fijo), las lesiones dependerán de sendos factores: de un lado, la posición dentro del vehículo; de otro, el uso de mecanismos de contención. Por cuanto hace a lo primero, las lesiones del conductor podrán producirse en cabeza, tórax o extremidades (dependiendo si se produce una proyección ascendente o descendente), siendo de destacar, en atención a la posición en el vehículo, las producidos por el impacto del volante y por la columna de dirección, así como la especial incidencia de los daños en el lado izquierdo del cuerpo. El copiloto está sujeto al cuadro análogo, pero con mayor incidencia en el lado derecho y con la salvedad dada por la ausencia de lesiones producidas por el volante y la dirección; la situación de los pasajeros de los asientos traseros es análoga, pudiendo ver más o menos dañada la parte del cuerpo más cercana a la ventanilla correspondiente.

Buena parte de estas lesiones podrán evitarse mediante el uso de sistemas de seguridad pasiva, que, en impactos de baja energía actúan como verdaderos salvavidas. Aun así, es importante tener presentes también los riesgos que estos elementos pueden provocar: en el caso del cinturón de seguridad, excoriaciones, abrasiones o quemaduras por fricción (transversal en la dirección del cinturón y lineal en el abdomen); fracturas costales y/o del esternón (transversales en la dirección indicada) y/o lesiones viscerales (contusiones pulmonares y cardiacas, pero también, por la porción horizontal del cinturón, en las vísceras abdominales). Por cuanto hace al airbag, puede provocar quemaduras en miembros superiores, luxación o subluxación de la articulación temporomandibular, lesiones oculares, irritación de vías aéreas (gases)..., incluso, en casos extremos, lesiones del raquis medular y paro cardiaco (commotio cordis).

Las lesiones que se producen como consecuencia de las colisiones laterales (en un cruce o en caso de golpe lateral contra objeto fijo) son parecidas a las producidas en un choque frontal, aunque su intensidad varía en función del lado siniestrado y de la presencia de otro individuo interpuesto que actúe como protección; en cualquier caso, con carácter general presentan menor letalidad que las frontales. 
Sea como fuere, en cualquiera de los dos casos es preciso tener presente el riesgo de vuelco, dada su alta letalidad cuando no se utilizan mecanismos de sujeción, sobre todo en los casos en que se produce una eyección (parcial o, sobre todo, total), con el riesgo de aplastamiento y mutilación que trae aparejada.

Frente a los siniestros apuntados, el menor nivel de lesividad lo presentan las colisiones por alcance, cuya consecuencia clásica es el latigazo cervical (whiplash).

Por cuanto hace a los accidentes en ciclomotores, las principales causas de muerte se vinculan con la conducción imprudente o poco cuidadosa, la intoxicación por alcohol o drogas, factores ambientales o derivados de la carretera..., pero también por la falta de visión de la moto por parte del vehículo que colisiona. Dada la naturaleza del vehículo y la dinámica del accidente, son de destacar por su gravedad las lesiones en cabeza (incluso portando casco) y cervicales, sin perjuicio, claro está, de posibles lesiones internas, fracturas en extremidades, abrasiones, excoriaciones, etc.

En fin, en el caso de los ciclistas, los accidentes no suelen provocar lesiones de especial gravedad salvo, por supuesto, los casos de atropello, causa de daños primarios (consecuencia del impacto) y secundarios (derivados de la caída), cuya gravedad depende, fundamentalmente, de la velocidad a que se produce el impacto, así como a la forma de producirse la caída.

Conviene no olvidar, para finalizar, que el conductor también pude verse afectado por el riesgo de accidente de circulación en calidad de peatón, pudiendo ser atropellado cuando abandona el habitáculo por razón de su trabajo o por cualquier otra circunstancia. En efecto, el conductor también puede ser víctima de atropellos por otros vehículos mientras trabaja en el suyo junto a la carretera, durante el repostaje, en el proceso de cambio de neumáticos o de reparación de averías o en las labores de carga y descarga. A este respecto, es preciso tener presente que la velocidad, el tipo de vehículo, la existencia de frenado y la estatura de la víctima actúan conjuntamente provocando diferentes situaciones, de modo que el peatón puede verse lanzado hacia arriba o hacia delante o ser tumbado. Sea como fuere, el atropello genera un patrón de lesiones (primarias y secundarias) característico: causadas por el paso del neumático sobre la piel, heridas "figuradas" por la acción de las distintas partes del vehículo, heridas "de defensa" (causadas por el golpe de la defensa del vehículo contra las extremidades inferiores, causando habitualmente fracturas), heridas al caer sobre el capó o el parabrisas, etc.

Para concluir con los riesgos mecánicos, se efectúa somera mención a otros posibles: caídas a distinto nivel, como, por ejemplo, caídas al subir o al bajar del vehículo (o en tareas de carga/descarga); caídas al mismo nivel, como, por ejemplo, debidas resbalones en el asfalto al salir del vehículo por el motivo que sea; aplastamientos, golpes y choques, como por ejemplo, lesiones por aplastamiento o choques y golpes producidos por herramientas manuales; incendio y explosión (su origen puede ser mecánico, físico, químico, eléctrico...), que puede ser ocasionado por un accidente de circulación o por fallos en el vehículo (circuito eléctrico, calentamientos del motor, fugas de combustibles, sistema de baterías, etc.). 
2. Riesgos físicos. Deben considerarse, fundamentalmente, ruido, vibraciones, ambiente térmico, quemaduras frías o calientes, calidad del aire, radiaciones, iluminación y electrocución.

\subsection{Riesgos químicos y biológicos}

En relación a esta cuestión, la Profra. Dra. Natalia Ordóñez Pascua puso de manifiesto como el desempeño de la tarea de conductor -en mayor medida el transporte de mercancías por carretera- lleva implícito una serie de riesgos asociados a diferentes aspectos de la actividad laboral. Es posible así discernir entre aquellos asociados a la seguridad, los ergonómicos, los psicosociales y los llamados riesgos higiénicos, entre los cuales se encuentra la exposición a contaminantes y agentes químicos y biológicos.

Por cuanto aquí importa, el riesgo aparece desde las primeras tareas de carga y repostaje. Cuando lo transportado son productos químicos o biológicos, a la exposición de riesgos inherentes al transporte cabe añadir los concretos de la carga manipulada.

Respecto a los agentes químicos, la normativa al efecto viene dada por el Real Decreto $374 / 2001$, de 6 de abril, sobre la protección de la salud y seguridad de los trabajadores contra los riesgos relacionados con los agentes químicos durante el trabajo que, en el marco de la Ley 31/1995, de 8 de noviembre, de Prevención de Riesgos laborales, establece en art. 1 el ámbito de aplicación a aquellos agentes químicos peligrosos que estén o puedan estar presentes en el lugar de trabajo, sin perjuicio de las disposiciones más rigurosas o específicas en la materia contenidas en el Real Decreto 2115/1998, de 16 de octubre, sobre transporte de mercancías peligrosas por carretera.

Define la primera de las citadas normas (art. 2) algunos términos que no es posible obviar a la hora de calificar a un riesgo como químico:

1. Agente químico: todo elemento o compuesto químico, por sí solo o mezclado, tal como se presenta en estado natural o es producido, utilizado o vertido, incluido el vertido como residuo, en una actividad laboral, se haya elaborado o no de modo intencional y se haya comercializado o no.

2. Exposición a un agente químico: presencia de un agente químico en el lugar de trabajo que implica el contacto de éste con el trabajador, normalmente por inhalación o por vía dérmica.

3. Peligro: la capacidad intrínseca de un agente químico para causar daño.

4. Riesgo: la posibilidad de que un trabajador sufra un determinado daño derivado de la exposición a agentes químicos. Para calificar un riesgo desde el punto de vista de su gravedad, se valorarán conjuntamente la probabilidad de que se produzca el daño y la severidad del mismo.

5. Agente químico peligroso: agente químico que puede representar un riesgo para la seguridad y salud de los trabajadores debido a sus propiedades físicoquímicas, químicas o toxicológicas y a la forma en que se utiliza o se halla presente en el lugar de trabajo. Se consideran incluidos en esta definición, en particular: 
6. Actividad con agentes químicos: todo trabajo en el que se utilicen agentes químicos, o esté previsto utilizarlos, en cualquier proceso, incluidos la producción, la manipulación, el almacenamiento, el transporte o la evacuación y el tratamiento, o en que se produzcan como resultado de dicho trabajo.

Por tanto, la primera labor consiste en identificar aquellas sustancias que tienen cabida en el concepto citado y delimitadas éstas se pondrán en marcha las medidas de prevención correspondientes $\mathrm{y}$, en su caso, las de protección específicas ante la imposibilidad de eliminar totalmente el riesgo.

Cabe añadir el necesario respeto a lo reglado en el RD 551/2006, de 5 de mayo, a cuyo tenor es establece como obligatorio el respeto al Acuerdo Europeo sobre Transporte Internacional de Mercancías Peligrosas por Carretera y disposiciones internacionales de aplicación (ADR, de 14 de marzo de 2013), firmado en Ginebra el 30 de septiembre si bien es anualmente actualizado. Ambos aluden a la necesaria formación en materia de prevención de los conductores de vehículos que lleven a cabo este tipo de transporte.

La exposición a contaminantes químicos puede llevarse a cabo en labores de mantenimiento del vehículo (reposición del electrolito de la batería, engrase de elementos, reposición de niveles de líquidos, exposición a gases de combustión procedentes tanto del propio vehículo como de la polución ambiental...). Sus consecuencias pueden ser más o menos severas y manifestarse desde una simple irritación o alergia en la piel hasta mareos, náuseas, pérdida de conocimiento... Entre las normas básicas para evitar el riesgo se encuentra la realización de las operaciones de mantenimiento básico según lo indicado en las instrucciones del fabricante de cada producto químico y siguiendo las instrucciones de la etiqueta, empleo en su caso de equipos de protección (guantes, mascarilla y gafas)para evitar el contacto con la piel y mucosas de los productos químicos, en lugares con escasa ventilación procurar mantener apagado el motor del vehículo, no comer, fumar o beber mientras se manipulen productos químicos y lavarse las manos después de cada manipulación...

En lo que al riesgo biológico se refiere, la normativa al uso se encuentra fundamentalmente en el RD 664/1997, de 12 de mayo, sobre la protección de los trabajadores contra los riesgos relacionados con la exposición a agentes biológicos durante el trabajo, que encomienda de manera específica, en su disposición final primera, al Instituto Nacional de Seguridad e Higiene en el Trabajo, la elaboración y mantenimiento actualizado de una Guía Técnica, si bien de carácter no vinculante, para la evaluación y prevención de aquellos asociados a la presencia de tales agentes. El transporte por carretera de esta mercancía habrá de estar a lo dispuesto a las normas antedichas de transporte de mercancías peligrosas por carretera y atender a la específica norma de tratamiento de lo transportado.

La labor de prevención comienza con las operaciones de recogida, transporte y manipulación de agentes biológicos en el lugar de trabajo que entrañan un riesgo de exposición para el personal que las realiza. Por lo tanto, desde la recepción de las muestras hasta la eliminación de los residuos generados, todas las fases deben estar debidamente sistematizadas. Son contemplados agentes biológicos propiamente 
dichos (cepas de microorganismos, cultivos, líneas celulares) como los materiales que los pueden contener, fundamentalmente excreciones, secreciones, sangre y sus componentes, líquidos corporales, tejidos, fluidos tisulares (muestras clínicas). El transporte de agentes biológicos se lleva a cabo a partir de un embalaje primario (estanco y debidamente etiquetado) que contiene el agente biológico o el material infeccioso y el recipiente secundario para su transporte resistente y a prueba de fugas con resistencia a la acción de los desinfectantes químicos.

La recogida y el transporte de los residuos debe ser realizada por un transportista autorizado e ir acompañada de la documentación preceptiva de seguimiento y control, en vehículos dotados de caja cerrada de seguridad que se desinfectarán periódicamente.

El personal que efectúa el transporte dispondrá de ropa de trabajo y de los equipos de protección individual necesarios además de formación sobre protocolos de actuación en caso de accidente o vertido.

\subsection{Riesgos psicosociales}

Concluyó la mesa redonda con la intervención realizada por el Prof. Dr. Juan José Fernández Domínguez en relación con los riesgos psicosociales, sistematizada en cuatro grandes bloques:

1. Factores desencadenantes de los riesgos psicosociales. Se aglutinan en torno a dos grandes grupos: De un lado, elementos derivados de otros riesgos con tratamiento propio en las Jornadas, tales como los musculoesqueléticos, los mecánicos y del ambiente laboral, los químicos y biológicos, la seguridad vial, los hábitos de vida poco saludables, la equipación y las condiciones técnicas, la organización y coordinación... De otro, diversos factores significados por los interesados como causa de riesgos psicosociales:

A) Jornada/tiempo de trabajo: tiempos prolongados de trabajo, horarios estrictos vinculados a complementos de productividad, trabajo a turnos, trabajo nocturno, largas rutas internacionales, flexibilidad horaria (jornadas elásticas o tiempos de puesta a disposición), escasos períodos de descanso y sueño insuficiente, etc.

B) Tareas rutinarias y repetitivas.

C) Aislamiento.

D) Entornos de trabajo peligrosos: contactos con "clientes-riesgo", atracos etc.

E) Necesidad de manifestar emociones: ambulancias, funerarias, grúas, experiencias en accidentes anteriores, etc.

F) Ambigüedad y conflictos de rol: trabajadores jóvenes e inexpertos/ trabajadores experimentados pero sin motivación.

G) Características personales: las cuatro con dimensión jurídica propia (origen, edad, género y capacidad) y las menos accesibles (adicciones, genética o "The Big Five").

H) Alteración de la vida personal y familiar.

I) Sobrecarga mental: demandas de pasajeros, atención a otros conductores, comportamientos en el medio de trasporte o en las vías de circulación, 
funciones adicionales (cobro, quebrantamiento de moneda, control de situación, etc.).

2. Consecuencias psicofísicas. Desgaste profesional (burn out), inseguridad contractual, estrés/depresión/ansiedad, adicciones (alcohol, drogas, medicamentos, etc.), violencia (interna -acoso- o externa), conflicto trabajofamilia...

3. Efectos en la organización. Se aprecian en distintos ámbitos; así, absentismo/abandono/despido; productividad empresarial, satisfacción, compromiso laboral; accidentes y daños a terceros; conductas laborales contraproducentes; conciliación vida laboral-personal-familiar...

4. Vías de intervención. Se analizan tres ejemplos de buenas prácticas:

A) El modelo "Trim Truckers" finés: cribado médico/intervenciones de distinto nivel en alimentación-ejercicio/psicólogo laboral.

B) El "sistema social" de la ATM italiana: análisis cuantitativo y cualitativo de sucesos peligrosos cada mes y reevaluación de riesgos y medidas/las "historias del trabajador" analizadas por el psicólogo y la prevención de la salud mental personalizada/acciones formativas generales (diferencia según nuevo ingreso o veteranía) y específicas (vida personal/familiar, drogas y reconversión profesional).

C) Las experiencias de FCC Delegación Tarragona-Lleida y el acuerdo sectorial del sector trasportes por carretera sobre control de alcohol, drogas y otras sustancias en Asturias. El plan integral frente a adiciones: elaboración participada/información-formación/detección precoz e intervenciones breves/tratamiento y seguimiento (movilidad-derivación)/ recuperación, rehabilitación y reinserción.

\section{FACTORES SUJETIVOS DE INCIDENCIA Y PROPUESTAS PARA LA REDUCCIÓN DE LA SINIESTRALIDAD Y MORBILIDAD EN EL TRABAJO DE CONDUCCIÓN}

\section{Circunstancias o características que pueden incidir en la producción del siniestro. Especial referencia a las variables género, edad, discapacidad y características de la relación (autónoma/por cuenta ajena)}

La jornada final comenzó con la intervención de la Profra. Dra. Beatriz Agra Viforcos, quien desgranó las circunstancias o características capaces de incidir en la producción del siniestro.

1. Factores que inciden en la producción de accidentes de tráfico. Siguiendo una clasificación tradicional y añadiendo a la misma nuevos planteamientos, el esquema seguido es el siguiente:

A) Factor humano. Incluye, al menos, errores en la percepción y toma de decisiones, acción de agentes que merman las capacidades, agentes inhibidores de la prudencia y búsqueda intencionada del riesgo y de emociones intensas (normalmente se exterioriza a través de la velocidad).

B) Factor vehículo. Existen distintos aspectos del vehículo que afectan a la seguridad: tipo de vehículo, antigüedad, estado y otros (por ejemplo, 
kilómetros recorridos y características del conductor que lo maneja). También aspectos vinculados a la relación conductor-vehículo: deficiencias en mantenimiento y reparación, desconocimiento del funcionamiento de la máquina y sus sistemas por parte del usuario y ergonomía de la información (estrés perceptivo del conductor).

C) Factor vía. Aspectos que pueden tener que ver con la calzada o vía en sentido estricto, el diseño del entorno de la vía, la climatología y otras incidencias temporales o medidas de control de tráfico y supervisión policial.

D) Otros factores. Algunos estudios ponen en conexión la siniestralidad con el entorno socioeconómico, señaladamente por el aumento de los vehículos a motor y el consiguiente mayor volumen de tráfico y por el envejecimiento de los usuarios de la vía. La pregunta es si también deben considerarse cuestiones como el género, la edad, la discapacidad o las características de la relación de trabajo.

2. Género. Las conclusiones clásicas han venido siendo que la seguridad vial depende de factores multicausales, de modo que el género interviene junto con edad, factores psicosociales, factores culturales; asimismo, que las mujeres tienen mayoritariamente comportamientos más responsables que los hombres en cuanto a la seguridad vial porque adquieren comportamientos y conductas más seguras.

Numerosos estudios confirman de un modo u otro, la incidencia del género en la sinuestralidad en carretera. Sirvan de muestra el Estudio siniestralidad vial y reincidencia por edad, sexo y lugar de residencia (Fundación Mutua Madrileña) y el Informe del Gobierno vasco "Perspectiva de género y seguridad vial" (febrero 2016).

3. Edad. También existe conexión entre edad y siniestralidad. Las franjas de mayor riesgo son los jóvenes (menores de 30 años) y los ancianos (mayores de 65 años). Por cuanto hace a la reincidiencia (Estudio Mutua Madrileña), los datos ofrecen una respuesta clara: los jóvenes de 18-29 años tienen un 75\% más de probabilidades de volver a provocar un accidente que el resto de la población.

4. Discapacidad. Debe ser tenida en cuenta desde dos puntos de vista:

A) Singularidades del conductor con discapacidad. Para obtener un permiso/licencia de conducir la normativa exige reunir las aptitudes psicofísicas y habilidades requeridas para cada clase de permiso o licencia. Tras las oportunas pruebas, se emite informe que declara al conductor apto, apto con condiciones restrictivas o adaptativas o no apto.

B) La conducción como causa de discapacidad. Cuatro de cada diez minusvalías se producen como consecuencia de accidentes de tráfico. El tráfico deja cada año parapléjicas a 500 personas.

5. Características de la relación de trabajo. ¿Existen diferencias entre los profesionales de la conducción atendiendo a si son autónomos o asalariados? La diferencia esencial reside en la propia legislación, que no sujeta a autónomos y asalariados a un régimen jurídico homogéneo en materia preventiva. La encuesta "Salud y Condiciones de Trabajo en el transporte de mercancías por carretera" (2005) refleja diferencias en la percepción de distintos factores de riesgo. 


\section{Propuestas para la reducción de la siniestralidad y morbilidad en el trabajo de conducción (mesa redonda)}

La última mesa redonda de las jornadas se conformó por la Profra. Dra. $\mathrm{M}^{\mathrm{a}}$ Anunciación Trapero Barreales, el Prof. Dr. Vicente Martín Sánchez, la Profra. Dra. Henar Álvarez Cuesta, el Prof. Dr. Roberto Fernández Fernández y la Profra. Dra. Susana Rodríguez Escanciano.

\subsection{Seguridad vial}

La Profra. Dra. $\mathrm{M}^{\mathrm{a}}$ Anunciación Trapero Barreales siguió en su discurso un guion a lo largo del cual se desarrollaron los aspectos siguientes, que sirvieron para recapitular gran parte de los aspectos tratados a lo largo de las jornadas, añadiendo la necesaria referencia a las medidas a seguir para mejorar el estatus quo existente:

1. Conceptos: accidente in itinere y accidente en jornada (incluye el accidente en misión.

2. Factores que intervienen en el accidente laboral: factor humano, vehículo, vía, entorno, gestión de la actividad empresarial.

A) El factor humano: especial atención al consumo de drogas, estupefacientes, medicamentos. La fatiga, el estrés, el sueño. El uso del móvil y otros dispositivos.

B) El vehículo: medidas de seguridad activa o primaria, seguridad pasiva o secundaria, seguridad terciaria.

C) La vía: el diseño, la planificación, la construcción, el mantenimiento. Componentes de la vía. Las señales.

D) El entorno: visibilidad, iluminación. Condiciones climatológicas.

E) Gestión de la actividad empresarial: aspectos como la planificación de las rutas, la programación del trabajo, el nivel de productividad exigido, las políticas de remuneración, la gestión de las comunicaciones, etc.

3. Plan de seguridad vial.

A) Fase de diagnóstico: características de la empresa, información sobre movilidad de los trabajadores, análisis accidentes laborales viales, condiciones reales de trabajo, gestión de los desplazamientos en la empresa.

B) Evaluación de riesgos: diferenciación entre accidentes in itinere/en jornada, colectivos prioritarios.

C) Plan: definición de los objetivos, selección de acciones, búsqueda de apoyos y colaboración (con empresas, Administraciones Públicas, Mutualidades, Fundaciones...).

D) Implantación del plan: planificación de las actividades a desarrollar, comunicación a los trabajadores, en su caso adecuación de instalaciones y equipos, procedimiento para el seguimiento.

E) Seguimiento/Evaluación: indicadores (de resultado/de actividad), análisis y evaluación de los indicadores, en su caso medidas correctivas o revisión de las inicialmente adoptadas. 
4. Catálogo de medidas o acciones para la prevención de accidentes laborales viales:

A) Acciones orientadas a influir sobre el factor humano.

a) Conductor desde la formación. Cursos de formación en seguridad vial, formación en conducción segura de vehículos, elaboración de un Manual para la prevención de accidentes, simulador de conducción, jornadas formación en seguridad vial.

b) Conductor desde la concienciación/sensibilización. Campañas divulgativas de concienciación en seguridad vial, vigilancia de la salud y consejo sanitario, seguridad vial en el entorno familiar, plan para promocionar uso del transporte público.

B) Acciones orientadas a mejorar la seguridad del vehículo. Plan de dotación de elementos de seguridad, criterios de seguridad en las flotas de vehículos de la empresa, plan de revisión y mantenimiento de la flota de vehículos, instalación de dispositivos alcolock.

C) Acciones orientadas a influir sobre la vía/el entorno. Señalización de riesgos, alertas de tráfico, mejoras acceso al centro de trabajo.

D) Acciones orientadas a la gestión empresarial:

a) Gestión de los desplazamientos. Servicios de autobús de ruta y lanzaderas, programa coche compartido, fomento desplazamientos en bicicleta, adaptación horarios de trabajo, gestión desplazamientos en misión, planificación rutas, gestión aparcamientos con criterios seguridad vial, subvención coste billetes transporte público, creación gestor desplazamientos.

b) Comunicaciones. Política clara sobre las comunicaciones, instalación de aplicaciones Email\&Drive.

\subsection{Hábitos de vida saludables}

El Prof. Dr. Vicente Martín Sánchez se ocupó de conectar la morbilidad en carretera con los hábitos de vida.

Entendemos por hábitos de vida saludable todas aquellas conductas y/o comportamientos que nos son propios y tienen un claro efecto sobre nuestra salud. Estos hábitos son los principales responsables del nivel de salud de las poblaciones y los individuos y están muy enraizados en el ambiente económico, social y cultural en el que nos desenvolvemos.

El ambiente laboral es uno de los escenarios donde más tiempo pasan la mayoría de los ciudadanos y por ello de los de mayor influencia en la salud individual y colectiva. En este sentido no es de extrañar que entre los escenarios prioritarios para promocionar la salud de los individuos y las poblaciones se encuentre el mundo laboral. Por un lado, la promoción de la salud en el entorno laboral es bueno para los trabajadores y la sociedad, pero por otro, contar con trabajadores sanos y motivados es bueno para las empresas e instituciones. De manera que, si el lugar de trabajo es un lugar promotor de la salud en sentido amplio, no solo en lo referido a las condiciones de trabajo, los beneficios individuales, sociales y empresariales serán óptimos. 
En pocas palabras, promoción de la salud significa hacer que las opciones más saludables sean las de más fácil elección por las personas, y en el caso que nos ocupa por los trabajadores. Si como hemos comentado, los hábitos de vida son los principales determinantes de la salud y los principales causantes de enfermedad, la promoción de hábitos de vida saludable debe de ser una prioridad en el trabajo, pero no solo los hábitos relacionados con el lugar de trabajo, también con los hábitos de vida del propio trabajador. Promocionar la actividad física, la alimentación sana y equilibrada, el no consumo de drogas legales o ilegales, facilitar y promover el descanso nocturno, etc., se puede realizar también desde el lugar de trabajo.

En el caso que nos ocupa, la conducción, es un paradigma de todo lo hablado hasta ahora. Los accidentes de tráfico o conducción son un problema relevante de salud pública a nivel mundial y más de tres cuartas partes de estos accidentes se deben a comportamientos humanos relacionados la mayoría de ellos con los hábitos insanos.

La promoción de estos hábitos se basa en tres aspectos fundamentales de la educación para la salud. Que sepamos que tiene influencia en nuestra salud; que queramos adoptar aquellos hábitos o comportamientos saludables y finalmente que podamos adoptar esos hábitos para lo que el ambiente, en este caso labora, es fundamental para su puesta en práctica.

Y un último aspecto a reseñar en esta breve introducción es comentar la paradoja de la prevención. Este fenómeno, puesto de manifiesto por Geoffrey Rose, son informa que pequeños riesgos en mucha población expuesta supone una mayor carga de enfermedad y muerte que grandes riesgos en poca población expuesta. Pequeños cambios de hábitos de vida en mucha población tienen un mayor efecto en la salud colectiva que grandes inversiones que alcanzan a una pequeña parte de la población.

\subsection{Planes de movilidad}

De explicar este novedoso instrumento se encargó la Profra. Dra. Henar Álvarez Cuesta, quien comenzó recordando como los accidentes de tráficos siguen constituyendo una de las principales causas de mortalidad; es más, 800 trabajadores han perdido la vida en horario laboral, según los datos de la Dirección General de Tráfico en 2014. Según cifras del Ministerio de Empleo, en el periodo enero-febrero de 2015 se han producido un total de 76.224 accidentes de trabajo con baja, de los cuales 10.827 fueron accidentes in itinere.

Para luchar contra ellos, evitarlos y llegar a su erradicación, como en tantas otras ocasiones, la prevención juega un papel vital y en este caso los planes de movilidad constituyen el arma por excelencia para lograrlo. Su finalidad consiste en reconducir los desplazamientos recurrentes que se efectúan todos los días por motivo de trabajo hacia modos de transporte social y ambientalmente más sostenibles. Por cuanto aquí importa, cabe destacar dos posibles significados de los planes de movilidad, ambos estrechamente relacionados: de un lado, el llevado a cabo desde el Derecho Urbanístico y por otro el pactado o implantado dentro de una empresa. 
1. En cuanto hace al primero, de conformidad con la Resolución del Parlamento Europeo, de 2 de diciembre de 2015, sobre movilidad urbana sostenible, la movilidad en la Unión Europea sigue en gran parte basada en el uso de vehículos privados de propulsión convencional y que, por consiguiente, el transporte europeo depende en un $96 \%$ del petróleo o sus derivados en lo que a sus necesidades energéticas se refiere, lo que representa aproximadamente una tercera parte del consumo total de energía.

El transporte urbano genera alrededor del $25 \%$ del total de las emisiones de CO2 y aproximadamente el $70 \%$ de todas las emisiones en las zonas urbanas responsables del cambio climático y que es el único sector de la UE cuyas emisiones de gases de efecto invernadero continúan aumentando, no en vano, según datos del Eurobarómetro Especial 406 publicado en 2013, aproximadamente el $50 \%$ de los ciudadanos europeos utiliza a diario el vehículo privado, mientras que solo el $16 \%$ utiliza el transporte público y el $12 \%$ la bicicleta. Sin embargo, cerca del $50 \%$ de los desplazamientos en las zonas urbanas no superan los $5 \mathrm{~km}$., y que, por ello, en numerosas ciudades podrían realizarse a pie, en bicicleta, en transporte público/colectivo o en cualquier otro medio de transporte, como los recorridos compartidos.

El Parlamento Europeo, por tanto, en la Resolución de 2015, expresa su convencimiento de que los planes de movilidad urbana sostenible a largo plazo, apoyados por las tecnologías de la información y las comunicaciones, son instrumentos importantes para facilitar soluciones adecuadas y en materia de movilidad segura a todos los ciudadanos; anima a las autoridades de los Estados miembros a que elaboren planes en materia de movilidad urbana sostenible que concedan la prioridad a los modos de transporte que producen menos emisiones, incluida la electromovilidad y los vehículos propulsados por combustibles alternativos, lo que engloba a los sistemas de transporte inteligentes; apoya el establecimiento de zonas de tráfico y de plataformas intermodales que concedan la prioridad al uso del transporte público; y pide a las ciudades que evalúen cuidadosamente las necesidades de los ciudadanos y de las empresas y las características específicas de los modos de transporte para garantizar la movilidad sostenible en las ciudades y que adopten las medidas necesarias para mejorar la calidad de vida en las ciudades fomentando un cambio modal hacia modos de transporte sostenibles, incluido el caminar y la bicicleta, y promoviendo una política intermodal y/o comodal integrada.

En consecuencia, para mejorar la movilidad urbana, parecen medidas la disminución de los precios del transporte público (59\%), la mejora del servicio de transporte público $(56 \%)$ y la mejora de las infraestructuras para bicicletas $(33 \%)$.

Para ello, el Parlamento considera que la Comisión debe analizar el impacto que tendrían en la sociedad las nuevas formas de movilidad basadas en el modelo de la economía compartida, en particular el uso compartido de vehículos; hace hincapié en que un transporte público altamente desarrollado, eficiente, asequible, seguro y accesible es una parte integral de un desarrollo urbano sostenible; destaca que los servicios de coches compartidos, recorridos compartidos y coches colectivos utilizan mejor los recursos existentes y contribuyen a reducir el número de coches en las 
ciudades; reconoce la importancia de los programas europeos de navegación por satélite Galileo y EGNOS y de las redes móviles de alta velocidad; apoya la elaboración de un marco regulador que permita el uso de nuevas formas de movilidad y de nuevos modelos de reparto que hagan un mejor uso de los recursos existentes; reconoce la calidad y la diversidad del empleo que ofrecen los operadores de transporte público y los beneficios asociados para la economía; anima a los Estados miembros a fomentar, donde proceda, el uso de la bicicleta; y, en fin, anima a las empresas privadas, las administraciones y las instituciones de la UE a que sigan mejorando los servicios de gestión de la movilidad para sus miembros, personal y visitantes; pide a la Comisión y a los Estados miembros que impulsen políticas destinadas a estimular a las empresas para que reduzcan los desplazamientos de ida y vuelta al lugar de trabajo, permitiendo y fomentando el teletrabajo y promoviendo el uso de las TIC y las teleconferencias, entre otras medidas; considera que las medidas de movilidad, como las coordinadas por la Plataforma Europea de Gestión de la Movilidad (EPOMM), poseen un gran potencial para resolver la congestión urbana y ofrecer accesibilidad para todos.

En el ámbito interno, la Ley 34/2007, de 15 de noviembre, de calidad del aire y protección de la atmósfera, hace una llamada a la negociación colectiva en su art. 16.2.a) para que considere la introducción de la movilidad sostenible dentro del contenido convencional. Desde el punto de vista normativo, resulta de interés reseñar las leyes promulgadas recientemente en materia de movilidad por las Comunidades Autónomas; así sucede con la pionera, Ley 9/2003, de 13 de junio, de la Comunidad Autónoma de Cataluña; y con las que siguen su estela (Ley 6/2011, de 1 de abril, de Movilidad de la Comunidad Valenciana; Ley 4/2014, de 20 de junio, Ley de Transporte Terrestre y Movilidad Sostenible de Illes Balears). Todas ellas toman en consideración, como es lógico, los trayectos destinados a trabajar, y prevén planes de movilidad sostenible teniendo en cuenta las áreas destinadas a la realización de actividad productiva.

2. Respecto al segundo, y por cuanto hace a los planes de movilidad diseñados en las empresas para propiciar un transporte más seguro para los trabajadores, además del impulso dado por el legislador, no cabe duda que los sindicatos juegan un papel fundamental en el trabajo por lograr un sistema de movilidad más social, ecológico y eficiente y una (quizá la mejor) de las vías para lograrlo es la negociación colectiva.

Sin embargo, a la hora de la verdad, escasos son los convenios que incorporan auténticos compromisos de sostenibilidad y protección medioambiental, e implantan planes de movilidad empresarial o planes de movilidad sostenible que reduzca los accidentes de trabajo in itinere y las emisiones contaminantes.

Los principales objetivos de un Plan de Movilidad Sostenible negociado habrían de ser: reducir la movilidad motorizada individual; disminuir los impactos ambientales producidos por el desplazamiento al trabajo; disminuir el consumo energético del desplazamiento al centro de trabajo; bajar el nivel de congestión circulatoria; colaborar a reducir el número de accidentes in itinere; garantizar la equidad en el acceso al puesto de trabajo; en fin, destaca la preocupación por la movilidad sostenible en las empresas como punto de partida para fomentar la integración de las mujeres e 
inmigrantes ( $\sin$ permiso de conducir), minimizar costes a la empresa (en materia de responsabilidad civil, recargos o sanciones administrativas) y reducir el impacto ambiental.

Para ello, las acciones propuestas son múltiples y en un elenco no exhaustivo cabe mencionar las siguientes: fomentar el uso de medios no motorizados; promover la transferencia de los modos de transporte privados individuales a los públicos colectivos; o la aplicación de un sistema de coche compartido.

De manera específica se propone adoptar la figura de un coordinador de movilidad en el que se aúnen distintas iniciativas de aplicación según la situación, necesidades y características de la empresa.

3. No sólo con un fin preventivo de los accidentes in itinere, la movilidad sostenible también forma parte de la Estrategia Española de Desarrollo Sostenible de 2007, la cual "exige mejorar la gestión de los sectores productivos, promover la adopción de mejoras tecnológicas, optimizar las redes de transporte tanto de energía como hidráulicas, facilitar el cambio modal en el uso del transporte, controlar las emisiones de gases de efecto invernadero y de otras sustancias contaminantes y aumentar la valorización económica de los residuos, así como formar, informar y concienciar a los ciudadanos y las empresas de los beneficiosos de estas medidas".

En este último sentido, el transporte de personas y mercancías dentro de un plan de movilidad sostenible conforma un sector de actividad vinculado al empleo verde, como el resultado de aplicar políticas de movilidad sostenible generadoras de empleo en condiciones de trabajo decente. Como ejemplos, cabe destacar la apuesta por vehículos con menos consumo de combustible; híbridos-eléctricos, eléctricos y con pilas de combustible; compartidos; transporte público; transporte no motorizado (utilizar la bicicleta, caminar) y cambios en las políticas de utilización de la tierra y pautas de asentamiento (para reducir la distancia y la dependencia del transporte motorizado.

\subsection{Organización, coordinación, participación}

El Prof. Dr. Roberto Fernández Fernández pormenorizó algunos aspectos de la legislación preventiva, relacionados con diversos aspectos organizativos, con capacidad para incidir en la materia desde el punto de vista de una mejor gestión.

1. Organización de la actividad preventiva. La Ley de Prevención de Riesgos Laborales y, en su desarrollo el Reglamento de los Servicios de Prevención, obliga al empresario a organizar la actividad preventiva dentro de la empresa, si bien pone a su alcance las tres posibilidades fundamentales, habida cuenta de que "en cumplimiento del deber de prevención de riesgos profesionales, el empresario designará uno o varios trabajadores para ocuparse de dicha actividad, constituirá un servicio de prevención o concertará dicho servicio con una entidad especializada ajena a la empresa" (art. 30.1 LPRL). Cada una de estas hipótesis plantea singularidades y cuenta con sus ventajas e inconvenientes, oportunamente desgranadas en la exposición. 
2. Coordinación entre empresarios. El art. 24 LPRL, y en su desarrollo el RD $171 / 2004$, establecen la obligación de cooperación en la aplicación de la normativa en materia preventiva para todas aquellas empresas cuyos trabajadores coincidan en el desarrollo de su actividad en un mismo centro de trabajo. A tal fin, establecerán los medios de coordinación que sean necesarios en cuanto a la protección y prevención de riesgos laborales y la información sobre los mismos a sus respectivos trabajadores, en los términos previstos en el apartado 1 del artículo 18 de esta Ley (art. 24.1 LPRL).

Por su parte, el empresario titular del centro de trabajo adoptará las medidas necesarias para que aquellos otros empresarios que desarrollen actividades en su centro de trabajo reciban la información y las instrucciones adecuadas, en relación con los riesgos existentes en el centro de trabajo y con las medidas de protección y prevención correspondientes, así como sobre las medidas de emergencia a aplicar, para su traslado a sus respectivos trabajadores (art. 24.2 LPRL). Si sus trabajadores desarrollan actividades en el centro de trabajo, debe cumplir las obligaciones de cooperación impuestas a todos los concurrentes (art. 6 RD 171/2004), correspondiéndole la iniciativa para establecer los medios de coordinación (art. 12 RD 171/2004), la designación de los coordinadores y, en su caso, la ampliación de sus funciones (art. 14.1 RD 171/2004). Además, a él compete en todo caso informar y dar instrucciones a los otros empresarios (y a los autónomos), antes del inicio de actividades y cuando se produzcan cambios relevantes, sobre los riesgos existentes en el centro de trabajo, las medidas de protección/prevención correspondientes y las medidas de emergencia (arts. 24.2 LPRL y 7 y 8 RD 171/2004).

Cuando el empresario principal contrate obras o servicios correspondientes a su propia actividad para ser desarrollados en sus centros de trabajo, debe vigilar que los contratistas, subcontratistas o autónomos contratados cumplen las obligaciones preventivas que les competen (arts. 24.3 LPRL, 10.1 RD 171/2004 y 8.4 Ley 20/2007). Respecto a los empleados de las contratistas o a los autónomos que no presten servicios en su centro de trabajo, la principal sólo asume una obligación: si operan con maquinaria, equipos, productos... proporcionados por ella, debe trasladarles la información procedente de fabricantes, importadores y/o suministradores (arts. 24.5 y 41 LPRL).

3. Participación y representación de los trabajadores. La LPRL otorga gran importancia a la participación de los trabajadores (habitualmente plasmada en derechos de información y consulta), reconociéndole una triple condición: es un principio general de prevención (art. 2 LPRL); es un derecho de los trabajadores (art. 34 LPRL), y su garantía es un deber empresarial (art. 18 y Capítulo V LPRL).

En cualquier caso, esta participación suele llevarse a efecto a través de representantes; en concreto, a los unitarios y sindicales les corresponde, en los términos recogidos en la normativa de aplicación, "la defensa de los intereses de los trabajadores en materia de prevención de riesgos en el trabajo", para lo cual "ejercerán las competencias que dichas normas establecen en materia de información, consulta y negociación, vigilancia y control y ejercicio de acciones ante las empresas y los órganos y tribunales competentes" (art. 34.2 LPRL). Junto a ellos, la LPRL contempla canales específicos de participación y representación en materia preventiva: 
A) Los delegados de prevención, que "son los representantes de los trabajadores con funciones específicas en materia de prevención de riesgos en el trabajo" (art. 35.1 LPRL).

B) El comité de seguridad y salud, que "es el órgano paritario y colegiado de participación destinado a la consulta regular y periódica de las actuaciones de la empresa en materia de prevención de riesgos" (art. 38.1 LPRL) y está formado, de una parte, por los delegados de prevención y, de otra, por el empresario y/o sus representantes en número igual (art. 38.2 LPRL). Cabe tanto el comité de seguridad y salud conjunto, por analogía con el regulado en el Estatuto de los Trabajadores, como el comité intercentros en las empresas con varios centros dotados de comité de seguridad y salud (art. 38.3 LPRL).

C) Instancias de participación y representación previstas en convenio. El art. 35.4.pfo. $2^{\circ}$ LPRL permite al convenio otorgar las competencias reconocidas en la LPRL a los delegados de prevención a órganos específicos de origen convencional, teniendo en cuenta que "dichos órganos podrán asumir, en los términos y conforme a las modalidades que se acuerden, competencias generales respecto del conjunto de los centros de trabajo incluidos en el ámbito de aplicación del convenio o del acuerdo, en orden a fomentar el mejor cumplimiento en los mismos de la normativa sobre prevención de riesgos laborales".

\subsection{Equipamiento y condiciones técnicas de los vehículos}

La mesa redonda se cerró con la intervención de la Profra. Dra. Susana Rodríguez Escanciano, quien habló de lo relativo al equipamiento y condiciones técnicas de los vehículos, señalando que, entre las actuaciones a adoptar para evitar (o al menos reducir) la elevada accidentabilidad obrante en el sector analizado, ocupa un lugar muy destacado el hecho de que el vehículo cuente con un equipamiento técnico óptimo y con unos dispositivos de seguridad idóneos, no en vano, y como ha señalado el Tribunal Supremo, "uno de los requisitos para que la circulación por calles y carreteras se realice de la forma adecuada es, sin duda, que los vehículos que las transiten se encuentren en correcto funcionamiento, pues sus deficiencias mecánicas y estructurales pueden incidir, y de hecho inciden, en la producción de accidentes, con las consiguientes secuelas que ello comporta" (STS, Cont-Admtivo, 13 octubre 1997), singularmente manifiestas para los trabajadores que prestan sus servicios en los mismos.

La propia Ley 16/1987, de 30 de julio, de Ordenación de los Transportes Terrestres, en su art. 55, sienta con total rotundidad que "los vehículos con los que se realicen los transportes públicos y privados... deberán cumplir las condiciones técnicas que resulten exigibles según la legislación industrial, de circulación y seguridad".

Cuando el medio de circulación se convierte en el lugar de trabajo, tal y como prevé el art. 1.2 a) Real Decreto 486/1997, de 14 de abril, surgen, para el empresario, una serie de obligaciones preventivas de carácter general: evitar los riesgos, evaluar las amenazas inevitables, combatir las amenazas en su origen, adaptar el trabajo a la persona, tener en cuenta la evolución de la técnica, sustituir los factores peligrosos por los que entrañen menor o ningún peligro, planificar la prevención, anteponer la 
protección colectiva a la individual y dar las debidas instrucciones a los trabajadores. Complemento indispensable de este deber genérico de tutela es la obligación, más específica pero no menos importante, de poner a disposición del asalariado un medio de transporte dotado de los suficientes elementos de seguridad y con óptimas condiciones de acondicionamiento, máxime cuando es dicho instrumento la herramienta fundamental de trabajo.

Un dilatado elenco de normas jurídicas, de diferente rango y condición, confluyen en esta materia, exigiendo un enorme esfuerzo sistematizador en aras a clarificar un panorama en exceso complicado. A tal fin -y en una primera aproximación-, procedería efectuar un estudio diferenciado de los requisitos técnicos a cumplir por los distintos tipos de vehículos implicados en el transporte por carretera, siguiendo a tal efecto la clasificación establecida en el Real Decreto 2822/1998, de 23 de diciembre, por el que se aprueba el Reglamento General de Vehículos, cuyo anexo II.C, distingue, atendiendo a los "criterios de utilización", los siguientes: "escolar, escuela de conductores, urbano, corto recorrido, largo recorrido, derivado de camión, plataforma, caja abierta, portacontenedores, jaula, botellero, portavehículos, silo, basculante, dumper, batería de recipientes, caja cerrada, capitoné, blindado, isotermo, refrigerante, frigorífico, calorífico, cisterna, cisterna isoterma, cisterna refrigerante, cisterna frigorífica, cisterna calorífica, góndola, todo terreno, taxi, alquiler, autoturismo, ambulancia, servicio médico, funerario, bomberos, RTV, taller o laboratorio, biblioteca, tienda, exposición u oficinas, grúa de arrastre, grúa de elevación, basurero, hormigonera, vehículo para ferias, estación transformadora móvil, extractor de fangos, autobomba, grupo electrógeno, comprensor, carretilla transportadora elevadora, barredora, bomba de hormigonera, perforadora, excavadora, retro-excavadora, cargadora, cargadora retro-excavadora, traílla, niveladora, compactador vibratorio, compactador estático, riego asfáltico, pintabandas y quitanieves".

Ahora bien, afrontar un análisis de las condiciones físicas y ergonómicas exigidas para los vehículos utilizados en cada una de las categorías enunciadas pondría enseguida de manifiesto cómo muchas de ellas presentan infinidad de aspectos comunes provocando reiteraciones innecesarias. Un racional esfuerzo de síntesis obliga, por tanto, a centrar la atención, primero, en las condiciones técnicas generales que deben de cumplir todos -cualquiera que sea su perfil- los vehículos de motor, sus partes y sus piezas (art. 11 Real Decreto 2822/1998), sin dejar de descender, después, al detalle de algunas especialidades aplicables a determinados modelos dotados de regulación propia (transporte escolar, de viajeros, mercancías peligrosas, sanitario y funerario, de animales, para la extinción de incendios y autotaxi).

Al tiempo, es menester aclarar también de entrada que, a los efectos del objeto y finalidad de este estudio, no se puede prescindir del análisis, como paso previo, de una serie de trámites administrativos a observar por cualquier medio de transporte antes de su puesta en circulación, no en vano la Ley 16/1987, de 30 de julio, de Ordenación de los Transportes Terrestres, pretende combinar en este marco el principio de libre economía y el de mercado con el de ejercicio de facultades públicas, correspondiendo a los poderes gubernativos la misión de procurar la eficaz prestación de los servicios de titularidad pública, así como las funciones de policía o fomento de 
los de titularidad privada (art. 4). En consonancia, la legislación de transportes regula las obligaciones de homologación, autorización y registro, así como de inspección técnica, sobre las cuales se va a insistir seguidamente. Todo ello sin olvidar cómo el Real Decreto Legislativo 6/2015, de 30 de octubre, por el que se aprueba el texto refundido de la Ley sobre Tráfico, Circulación de Vehículos a Motor y Seguridad Vial, regula tres obligaciones en relación con la circulación de los vehículos: la obtención del permiso de circulación dirigido a comprobar que están en perfecto estado (art. 66), la disposición de la documentación de sus características (art. 67) y la colocación de la matrícula (art. 68).

\section{APLICACIÓN DE UN PLANTEAMIENTO CAUSAL EN LA EPIDEMIOLOGÍA DE LAS LESIONES A CONSECUENCIA DEL TRÁFICO}

La conferencia de clausura corrió a cargo del Prof. Dr. Eladio Jiménez Mejías, de la Universidad de Granada, quien enfocó su ponencia desde un planteamiento epidemiológico.

Cadena epidemiológica de las lesiones consecuencia del tráfico (lct). Se trata de un modelo epidemiológico originalmente desarrollado para explicar, a nivel ecológico, las diferencias entre países o regiones en las tasas de mortalidad por AT, así como su evolución temporal. Según este modelo, que aplicado a nivel agregado se conoce usualmente como análisis de descomposición, la variabilidad geográfica y/o temporal en las tasas de mortalidad es el resultado de la variabilidad de sus tres componentes: intensidad en la exposición (exposición / $\mathrm{N}$ habitantes), accidentalidad (accidentes / $\mathrm{N}$ unidades exposición) y letalidad (defunciones / $\mathrm{N}$ accidentes).

Puesto que, a nivel ecológico, es posible obtener indicadores para cada uno de los tres componentes anteriormente definidos, es posible descomponer las tasas de mortalidad de una unidad ecológica en estos tres teóricos componentes. Matemáticamente: Tasa de mortalidad $=$ Tasa de exposición $\mathrm{x}$ Tasa de accidentalidad $\mathrm{x}$ Tasa de letalidad.

La aplicación de estos modelos ha sido relativamente amplia en los últimos años. Sin embargo, una vez alcanzado este nivel de descomposición, la falta de información con el suficiente nivel de desagregación impide descender un escalón, a la hora de identificar cuáles son los factores determinantes de cada uno de los tres componentes antes citados.

Es evidente que el análisis de descomposición contiene, implícitamente, una formulación causal en términos secuenciales, que puede expresarse tanto a nivel ecológico como individual, y cuyo nivel de segregación (el número de elementos de la secuencia) podrá detallarse en mayor o menor medida, en función de que seamos capaces de identificar más o menos eslabones intermediarios relacionados con factores de riesgo específicos. Así, desde la perspectiva ecológica, el volumen de muertes por AT ocurrido en una población sólo puede ocurrir entre aquellos miembros de dicha población lesionados en el AT. Éstos, a su vez, serán una fracción del total 
de sujetos implicados en el conjunto de AT ocurridos. Finalmente, los AT sólo pueden darse entre las personas expuestas al riesgo de sufrirlos, que serán una parte de la población total. La representación de esta secuencia puede hacerse en forma de pirámide (Figura 1), que refleja gráficamente cómo el volumen de muertes no es más que una fracción relativamente pequeña -la cúspide--, que procede de una población general -la base--, que ha debido atravesar sucesivos escalones antes de alcanzar (por desgracia), la cima de la pirámide.

\section{Figura 1. Pirámide Causal de las LCT}

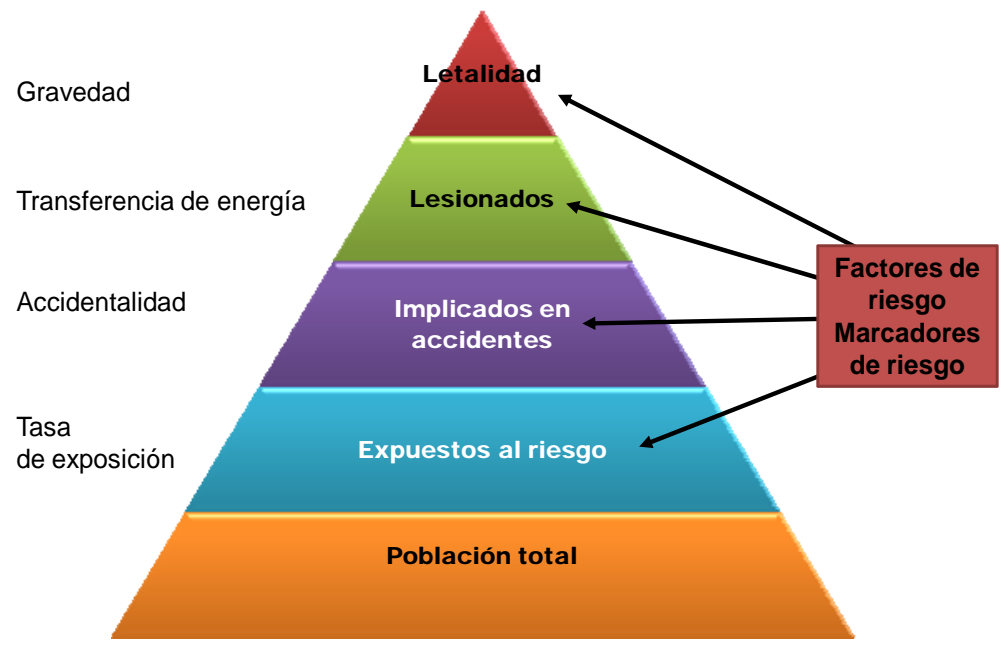

Como queda reflejado en la figura, la intensidad de paso de un escalón de la pirámide al inmediatamente superior depende de los componentes del modelo de descomposición mencionado anteriormente (con la salvedad de que, en la secuencia descrita en la pirámide, la letalidad aparece ahora descompuesta en lesividad (lesionados/ $\mathrm{N}$ accidentes) y letalidad propiamente dicha (defunciones/ $\mathrm{N}$ lesionados). La lesividad dependería, a su vez, de la intensidad de la transferencia de energía a los sujetos implicados en el AT, mientras que la letalidad se relacionaría con la gravedad (el pronóstico), de las lesiones.

No es difícil extrapolar este planteamiento secuencial a un abordaje causal individual de las LCT. Desde esta perspectiva, para que una persona muera por una LCT es necesario que previamente sufra una LCT, la cual sólo puede haberse producido tras haber sufrido un AT. Éste, a su vez, sólo puede haber ocurrido en un sujeto expuesto. Es fácil, a partir de este razonamiento, expresar el riesgo de muerte por AT (o cualquier otro desenlace indeseable), como el resultado de una cadena de eventos, cada uno de los cuales está asociado a un riesgo específico de aparición, en función del efecto de un conjunto de factores o marcadores de riesgo. Este planteamiento en términos de cadena causal de eventos permite, por una parte, descomponer el riesgo del desenlace final en términos de probabilidades condicionadas o, en última instancia, de hazards (de estar expuesto, de sufrir un accidente, de sufrir una lesión, 
de morir). Por otra, permite individualizar el efecto y la magnitud de los factores de riesgo separadamente sobre cada uno de los marcadores (periodos a riesgo, probabilidades condicionadas o hazards) asociados a cada eslabón de la cadena. La Figura 2 ilustra gráficamente la cadena causal de las LCT.

Figura 2. Cadena causal de las LCT

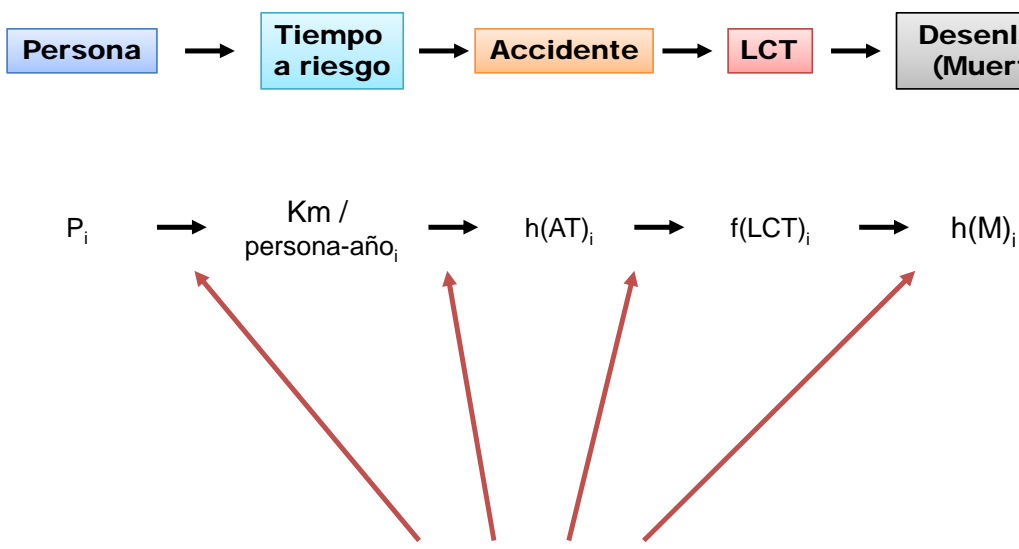

Factores de riesgo

En esta figura, la fila superior representa los eventos a tener en cuenta en la cadena causal; la fila inferior refleja la forma de estimar la intensidad de cada uno de ellos en un sujeto determinado $\left(\mathrm{P}_{\mathrm{i}}\right): \mathrm{h}(\mathrm{A})_{\mathrm{i}}$ sería la estimación del hazard de sufrir un AT a lo largo del período a riesgo en el sujeto $\mathrm{i}$; $\mathrm{f}(\mathrm{LCT})_{\mathrm{i}}$ sería la probabilidad de sufrir una LCT en el sujeto $i$, condicionada a haber sufrido un AT; finalmente, $h(M)_{i}$ sería el hazard de morir del sujeto i condicionado a haber sufrido una LCT.

El planteamiento de la causalidad de las LCT basado en una secuencia o cadena de eventos no es particularmente novedoso; ya el eje vertical de la matriz de Haddon delimita una secuencia temporal sobre la que actúan los diversos factores de riesgo. Probablemente, la aportación más relevante de este enfoque causal sea que, al centrarlo en la secuencia temporal y no tanto en el origen de los factores de riesgo (el eje horizontal de la matriz de Haddon), cambia la forma de orientar la metodología de estudio de la epidemiología analítica de las LCT: en lugar de centrarla sobre los factores de riesgo lo hace sobre los eventos de la cadena causal.

En conclusión, el método epidemiológico es plenamente aplicable a la epidemiología analítica de las LCT. Bajo esta perspectiva, es posible modelizar las LCT según una cadena causal constituida por diferentes eslabones. Así, el que un sujeto se accidente o finalmente resulte lesionado o muera, va a depender de una serie de factores $\mathrm{y} / \mathrm{o}$ marcadores de riesgo que actúan a diferentes niveles de esta cadena. El conocimiento de dichos factores y/o marcadores nos coloca sin duda en una ventajosa posición para su prevención y rompe con el sentido fortuito y no prevenible del término accidente. 